\title{
Spectral Measurements of Direct Solar Radiation and of Sun's Aureole (II)
}

- Near Infrared Region-

by

\author{
Keizo Murai \\ Meteorological Research Institute, Tokyo
}

(Received June 18, 1968)

\begin{abstract}
A new instrument improved in some points was constructed. Using this instrument measurements of direct solar radiation and aureole intensity were performed.

From the measurements of direct solar radiation, the spectral distribution of optical thickness of aerosol particles was obtained for each measurement. The spectral distributions obtained are classified into three types. The size distribution of aerosol particles corresponding to each spectral distribution of optical thickness is inferred for each measurement, by comparing with the theoretical calculations by FOITZIK and DEIRMENDJIAN. The size distribution inferred is the power law distribution with a hollow in the shorter side and a hump in the longer side of the range of radius. The wavelength region corresponding to the hollow and the hump are dependent on the type of spectral distribution of optical thickness.

Intensities of aureole at angular distance $\theta$ smaller than $5 \mathrm{deg}$. from the sun increase with increasing wavelength and those for $\theta>10 \mathrm{deg}$. are flat or slightly decrease with increasing wavelength. The ratio of monochromatic aureole intensity to that of the Rayleigh atmosphere increases with increasing turbidity factor $T(\lambda)=\left[\tau_{M}(\lambda)+\tau_{R}(\lambda)\right] / \tau_{R}(\lambda)$.

The slopes of angular distributions of aureole intensities corresponding to the three types of $\tau_{M}(\lambda)$ are different from each other and the slope for type $I$ is the largest among them. The dependency of slopes of the angular distributions on wavelength widely varies for each measurement. The relation between the angular distribution and the size distribution of aerosol particles were also investigated by using the two indices, that is, $F=\tau_{M}(0.4 \mu) / \tau_{M}(0.8 \mu)-\tau_{M}(0.8 \mu) / \tau_{M}(1.6 \mu)$ and $A_{D}=I_{r}(1.5 \mu, \theta) /$ $I_{r}(0.4 \mu, \theta)$.
\end{abstract}

\section{Introduction}

An analysis of spectral measurements of direct solar radiation and of the sun's aureole in ultraviolet and visible regions was described in Part I of this paper. In part II, the results of measurements which are extended to the near infrared region 
(to $\lambda 1.6 \mu$ ) are described. In order to facilitate the measurements of sky radiation in the infrared region, a new instrument improved in some minor points was constructed.

DEIRMENDJIAN (1959, 1960) calculated the spectral optical thickness for aerosol particles in the near infrared region assuming some kinds of size distributions of particles and showed that the effect of absorption of water vapour is predominant in the region longer than $2.0 \mu$ in wavelength. In these calculations he used the size distribution functions which are described by the combinations of power law size distributions.

FoITZIK (1965) calculated the spectral extinction coefficients of aerosol particles for the size distributions represented by the combinations of Gaussian groups and estimated the contribution of each Gaussian group to the extinction coefficients.

Few spectral measurements of solar radiation in the near infrared region are available outside of those obtained at the Smithsonian Institution. These measurements show the dependencies of optical thickness due to aerosol particles on the precipitable water vapour in the atmosphere.

GeBbIE et al. (1953) measured the horizontal transmission in the wavelength region 1.0 to $14 \mu$ along the eastern coast of Scotland with an optical transmissometer and investigated the relation between transmission and visibility or humidity.

Measurements of scattered radiation in the near infrared region were performed by ANTHONY (1953), VOLTZ and BULLRICH (1961). The resulst of VOLZ and BULLRICH show that the slopes of angular distributions of aureole intensities in the near infrared region differ appreciably from those of the visible region and they discussed the relation between angular distributions of aureole intensities and size distributions or optical and chemical properties of particles.

PRITCHARD and ELLIOTT (1960) measured the angular distribution of light scattered by haze or fog with a polar nephelometer and measured simultaneously the attenuation along the path with a portable transmissometer.

Among his recent investigations, DEIRMENDJIAN (1964) calculated the spectral extinction coefficients by using the size distribution function which is able to describe the size distribution of cloud particles as well as aerosol particles and then calculated the scattering intensity function for these size distributions assumed.

By comparing the measured values of spectral optical thickness and aureole intensities with those computed on the basis of the aerosol size distributions mentioned above (DEIRMENDJIAN, 1964; FOITZIK, 1965), we discuss the relation between spectral optical thickness and aerosol size distributions.

\section{Improvements on the instrument}

The old instrument was improved in some detailed parts, in order to obtain more precise measurements in the near infrared region. The points improved are as follows;

(1) Telescope The diameter of the telescope was enlarged in order to facilitate measurements of scattered radiation in the near infrared region, while the viewing 
angle of the telescope is kept the same as in the old instrument, namely $25^{\prime}$ half-angle.

(2) Double monochrometer In the old instrument, the adjustment of the slit width causes relatively large errors in measurements because the change of the slit width is continuous, but in the new instrument, the slit width is changed discretely. Then the measurement errors due to the adjustment of slit width are diminished.

(3) Selection of wavelengths In the old instrument, the two prisms are rotated continuously and the intensity of incident radiation is recorded continuously. In the new one, the two prisms stay for 3 seconds at the wavelength selected and are driven to the next wavelength selected in 0.5 seconds. Fourteen wavelengths are selected for measurement in the region $\lambda 0.4$ to $1.6 \mu$. This improvement has reduced the time required for the scanning of wavelengths and made it possible to detect whether the measurement at each wavelength is performed in stable state or not.

(4) Neutral filters In the old instrument, the semi-transparent quartz plate diffuser, which is used in adjusting the amount of incident radiation, causes rather large errors in measurements. In the new one, neutral filters are used for adjustment. Since the transmission of these filters varies with wavelength, their transmission was precisely calibrated for each wavelength.

The photograph of the new instrument is shown in Fig. 1.

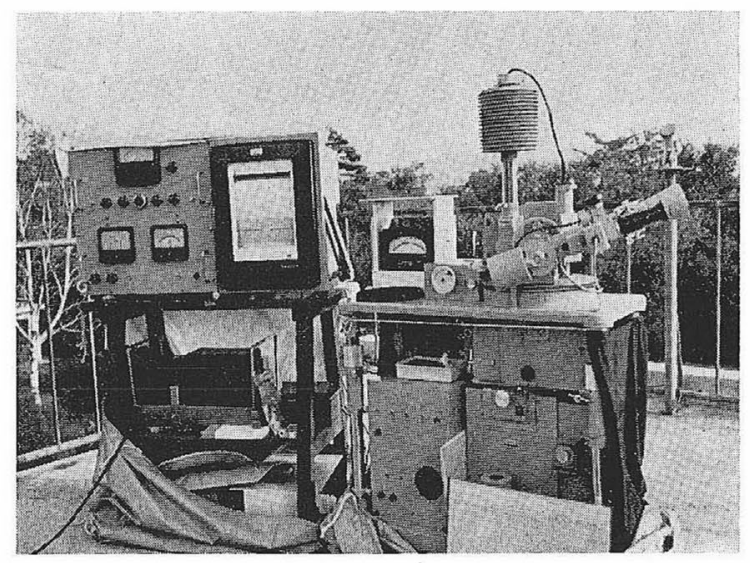

Fig. 1. Photograph of the new instrument which was improved to facilitate the measurement of sky radiation in the near infrared region.

\section{Results of Measurements}

The details of the measurement techniques were described in Part I of this paper. Here we will not repeat them.

The measurements were performed at Tateno $(40 \mathrm{~km} \mathrm{E}$ from Tokyo), Karuizawa $(150 \mathrm{~km} \mathrm{NW}$ from Tokyo, $1,000 \mathrm{~m}$ above sea level) and Tokyo. In the case of measurements of aureole intensities, the whole sky was photographed in order to show the state of clouds. At Tateno, the continuous records by Eppley pyrheliometer were used, to know the optical fluctuation of the atmosphere, 


\subsection{Measurements of direct solar radiation}

The spectral factors of the instrument, $r_{0}(\lambda)$, corresponding to the spectral energy of solar radiation outside the atmosphere were determined from the measurements of direct solar radiation with the method described in Part I. Generally, the ratio of the photocurrent corresponding to incident radiation to that of the reference lamp, $r(\lambda)$, around the noon scatters considerably around a mean value. Therefore, $r_{0}(\lambda)$ is determined by using the measured values of $r(\lambda)$ besides those around noon, if the values of $r(\lambda)$ and the record of the Eppley pyrheliometer besides those around noon are nearly stable. In the case of Tokyo, sometimes the atmospheric optical thickness is very large and consequently the intensity of direct solar radiation reaching the ground is so small that the values of $r(\lambda)$ for large optical air mass $M$ scatter widely, especially in the shorter wavelength region. Therefore, the errors of $r_{0}(\lambda)$ determined at Tokyo are the largest, especially in the shorter wavelength region. Some examples of $\log r(\lambda)$ versus $M$ curves for the determination of $r_{0}(\lambda)$ are sown in Fig. 2.

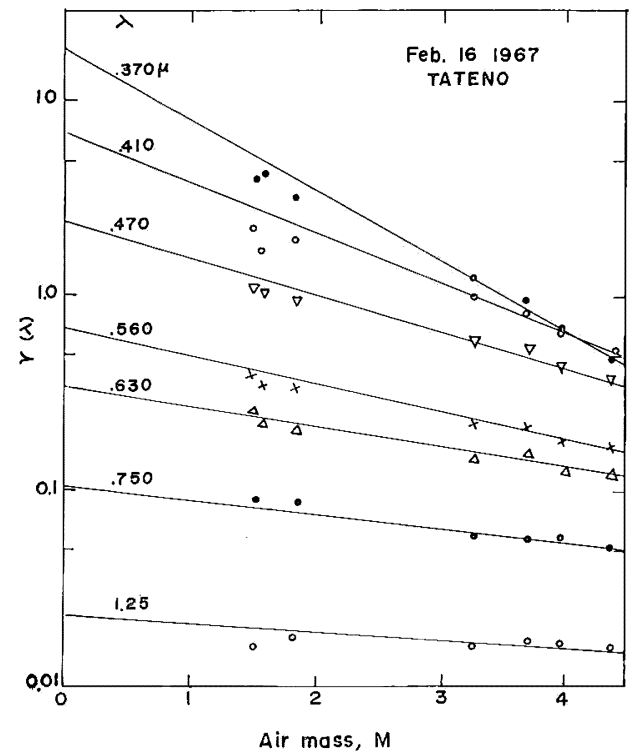

a

Fig. 2a. Some examples of $\log r(\lambda)$ vs. M curves for the determination of $r_{0}(\lambda)$ at Tateno. $r(\lambda)$ in the ordinate represents the ratio of the photocurrent for the incident radiation to that for the reference lamp. $r_{0}(\lambda)$ is the ratio corresponding to the solar radiation outside the atmosphere. $M$ in the abscissa is the optical air mass at the time of measurement.

Fig. 2b. Same as Fig. 2a but at Karuizawa.

Fig. 2c. Same as Fig. 2a but at Tokyo.

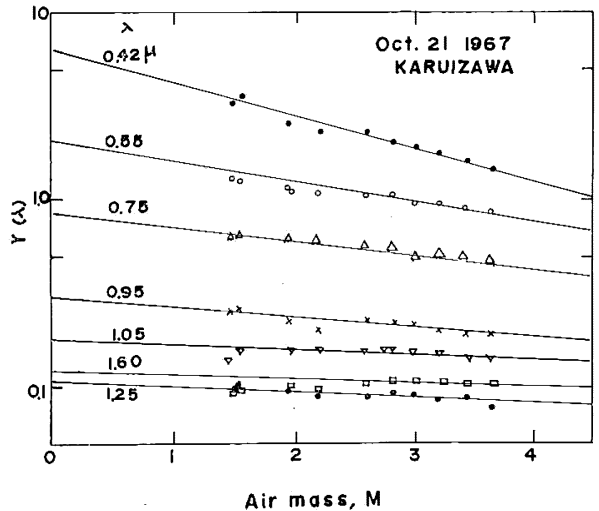

b

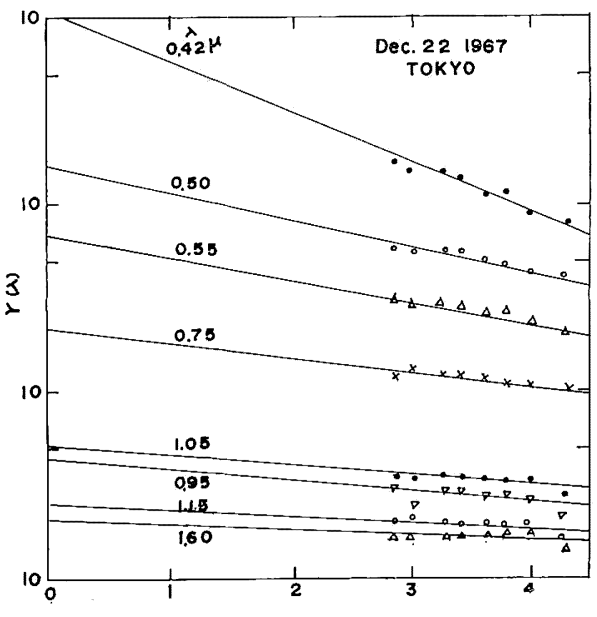

Air mas6, $M$

c. 
The ratio of $r(\lambda)$ to $r_{0}(\lambda)$ represents the monochromatic transmission of direct solar radiation in a turbid atmosphere. Denoting this quantity by $A(\lambda)$, the values of $A(\lambda)$ for Karuizawa is the largest and those of Tokyo the smallest on the average.

Table 1. Spectral transmission at each station for $M=1$.

\begin{tabular}{l|c|c|c|c|c|c|c|c|c|c}
\hline & \multicolumn{3}{|c|}{ Tateno } & \multicolumn{3}{c|}{ Karuizawa } & \multicolumn{3}{c}{ Tokyo } \\
\cline { 2 - 10 }$\lambda$ & max. & $\min$. & $\operatorname{mean}$ & $\max$. & $\min$. & mean & $\max$ & $\min$ & mean \\
\hline $0.40 \mu$ & 0.80 & 0.58 & 0.71 & 0.81 & 0.69 & 0.76 & 0.65 & 0.15 & 0.45 \\
0.55 & 0.86 & 0.67 & 0.76 & 0.87 & 0.77 & 0.82 & 0.79 & 0.25 & 0.58 \\
0.70 & 0.86 & 0.71 & 0.79 & 0.90 & 0.81 & 0.86 & 0.85 & 0.39 & 0.67 \\
0.85 & 0.88 & 0.74 & 0.81 & 0.91 & 0.83 & 0.88 & 0.87 & 0.48 & 0.72 \\
1.05 & 0.91 & 0.75 & 0.83 & 0.92 & 0.85 & 0.90 & 0.91 & 0.58 & 0.77 \\
1.50 & 0.95 & 0.78 & 0.87 & 0.95 & 0.88 & 0.92 & 0.93 & 0.70 & 0.82 \\
\hline
\end{tabular}

In Table 1 , the spectral values of $A(\lambda)$ for each station are shown.

\subsection{Spectral distributions of optical thickness due to aerosol particles}

The optical thickness due to aerosol particles $\tau_{M}(\lambda)$ is represented by $\tau_{M}(\lambda)=\tau(\lambda)$ $-\tau_{R}(\lambda)$, where $\tau_{R}(\lambda)$ is the optical thickness of molecular atmosphere and $\tau(\lambda)$ is the observed optical thickness. The optical thickness of ozone $\tau_{0 z}(\lambda)$ is neglected as mentioned in Part I.

The measurements of direct solar radiation were performed many times a day and the spectral optical thickness obtained from these measurements show the diurnal variations as shown in Figs. 3 through 7 . In general it is large around noon and the curve for each wavelength varies almost in parallel each other.

The curves for Feb. 18 at Tateno (Fig. 5) show no such increment around noon and smaller values compared to those for Feb. 16 or 17 (Fig. 3 or 4 ). The values of $\tau_{M}(\lambda)$ of Feb. 17 show a sudden decrease at about $15 \mathrm{~h}$. At that time the passage of a cold front is recognized from the records of meteorological elements at the station,

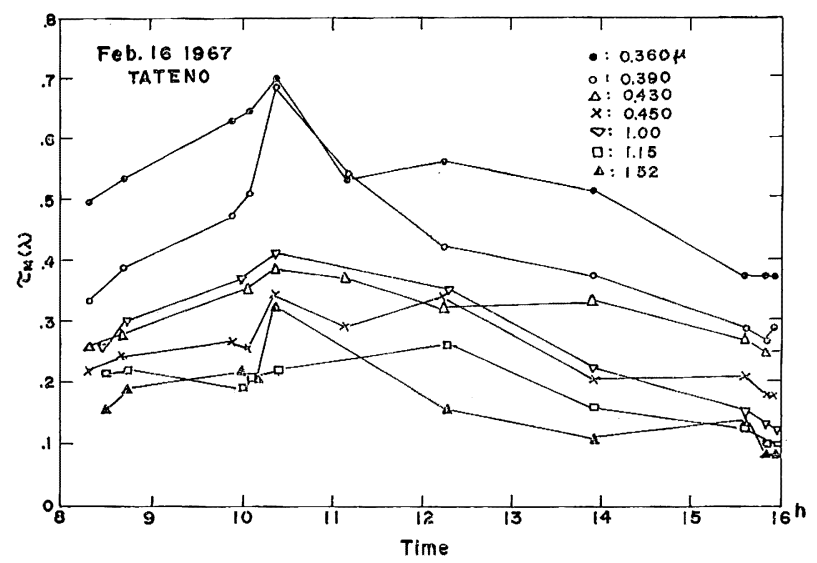

Fig. 3. Diurnal variation of optical thickness at Tateno on Feb. 16. 


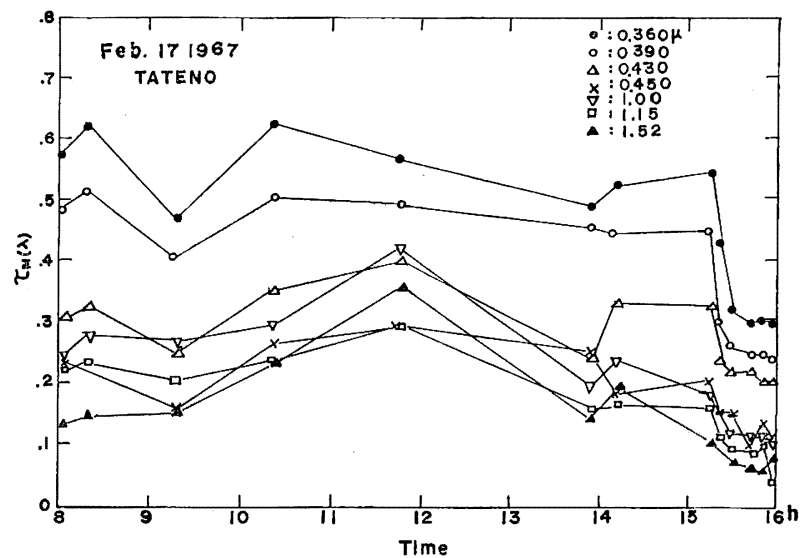

Fig. 4. Same as Fig. 3 but on Feb. 17.

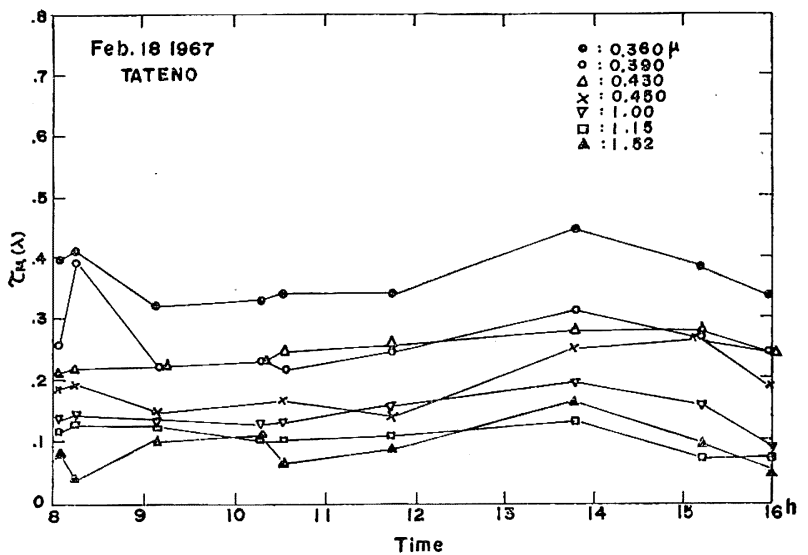

Fig. 5. Same as Fig. 3 but on Feb. 18 .

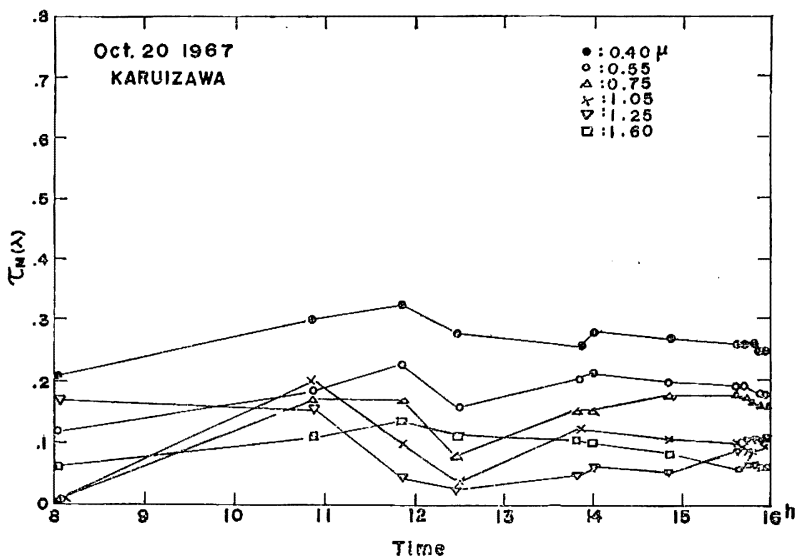

Fig. 6. Same as Fig. 3 but at Karuizawa on Oct. 20. 


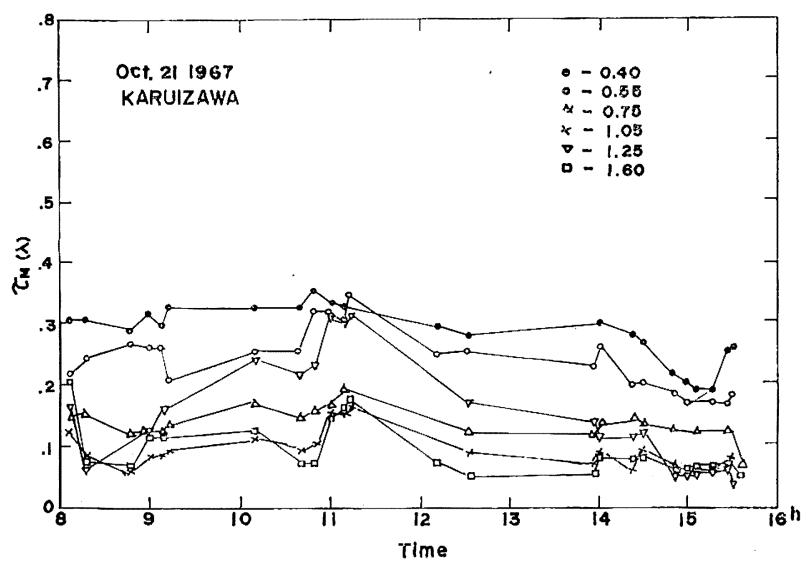

Fig. 7. Same as Fig. 6 but on Oct. 21.

and so the air mass was replaced by a fresh air mass. The above-mentioned sudden decrease of $\tau_{M}(\lambda)$ corresponds to this replacement by a new air mass. The curves of Feb. 18 reflect the effects of the inflow of the fresh air mass which continued until about the noon of the day.

Among the average values of $\tau_{M}(\lambda)$ for each station those of Karuizawa are the smallest and those of Tokyo the largest. In the wavelength region 0.4 to $0.55 \mu$ (hereafter we call this region the short region) $\tau_{M}(\lambda)$ at Karuizawa varies from 0.15 to 0.4, in the region 0.55 to $0.8 \mu$ (hereafter we call this region the intermediate region) from 0.1 to 0.2 and in the region 0.8 to $1.6 \mu$ (hereafter we call this region the IR region) from 0.05 to 0.2 . At Tokyo, $\tau_{M}(\lambda)$ varies from 0.3 to 2.0 in the short region, from 0.15 to 1.0 in the intermediate region and 0.07 to 0.5 in the IR region. At Tateno, $\tau_{M}(\lambda)$ varies from 0.15 to 0.55 in the short region, from 0.1 to 0.3 in the intermediate region and 0.05 to 0.3 in the $\mathrm{IR}$ region. The maximum, minimum and mean values of $\tau_{M}(\lambda)$ for each station are tabulated in Table 2 .

Table 2. Spectral optical thickness at each station for $M=1$.

\begin{tabular}{|c|c|c|c|c|c|c|c|c|c|}
\hline \multirow[b]{2}{*}{$\lambda$} & \multicolumn{3}{|c|}{ Tateno } & \multicolumn{3}{|c|}{ Karuizawa } & \multicolumn{3}{|c|}{ Tokyo } \\
\hline & $\max$ & $\min$ & mean & $\max$ & $\min$. & mean & $\max$ & $\min$. & mean \\
\hline $0.40 \mu$ & 0.54 & 0.22 & 0.35 & 0.37 & 0.21 & 0.28 & 1.99 & 0.45 & 0.88 \\
\hline 0.55 & 0.40 & 0.16 & 0.28 & 0.26 & 0.14 & 0.20 & 1.37 & 0.24 & 0.58 \\
\hline 0.70 & 0.34 & 0.15 & 0.24 & 0.21 & 0.11 & 0.16 & 0.95 & 0.17 & 0.43 \\
\hline 0.85 & 0.30 & 0.13 & 0.21 & 0.19 & 0.09 & 0.13 & 0.74 & 0.14 & 0.31 \\
\hline 1.05 & 0.29 & 0.10 & 0.19 & 0.17 & 0.08 & 0.11 & 0.54 & 0.11 & 0.27 \\
\hline 1.50 & 0.26 & 0.06 & 0.14 & 0.13 & 0.06 & 0.09 & 0.36 & 0.07 & 0.20 \\
\hline
\end{tabular}

In order to see the distributions of optical thickness due to aerosol particles with wavelength, $\tau_{M I}(\lambda)$ are plotted against wavelength $\lambda$ in logarithmic scale. The distribution curves are separated into two groups: one of them shows an almost linear curve and the other a rather indefinite one. The former, liner curves, mainly appear in the 


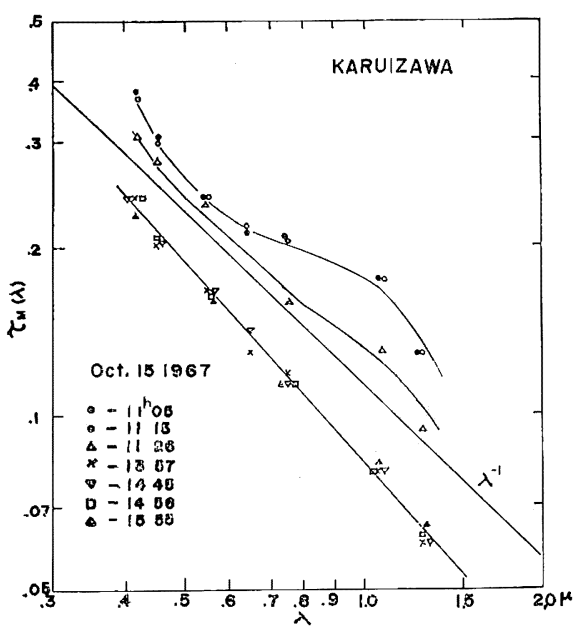

Fig. 8. Spectral distribution of optical thickness at Karuizawa on Oct. 15. Upper curves correspond to Type I in Sec. 4 and lower curve to Type III.

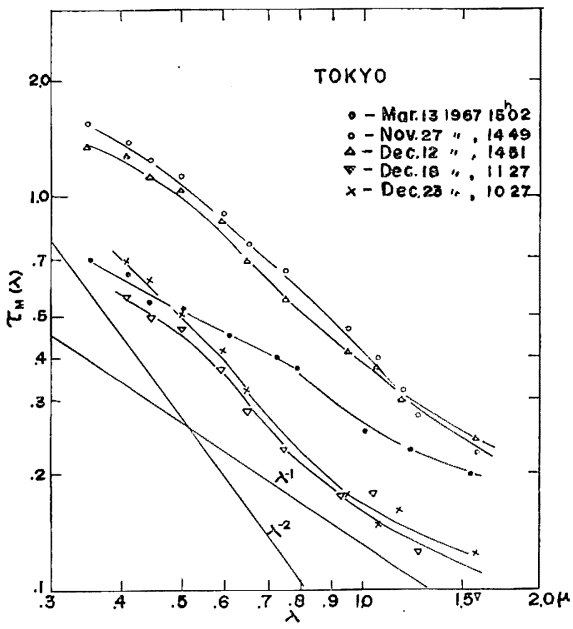

Fig. 9. Same as Fig. 8 but at Tokyo. The curves are Type III.

results of Tokyo. Some examples of this group are shown in Figs. 8 and 9. In these figures one might see that almost all the distribution curves show the linear decrease of $\tau_{M}(\lambda)$ with increasing wavelength in the short and the intermediate region, but their slopes gradually decrease in the IR region. In this case the distribution of $\tau_{M}(\lambda)$ in the short and the intermediate region is described by power function $C \lambda^{-r}$ in which $\gamma$ is between 1 and 2. In the IR region the slope of the distribution curve is slightly less than in the other regions.

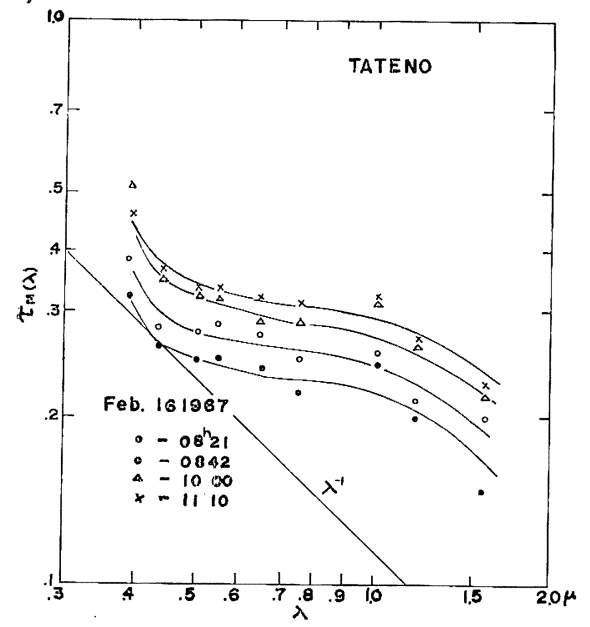

Fig. 10. Spectral distribution of optical thickness of Type I at Tateno on the morning of Feb. 16.

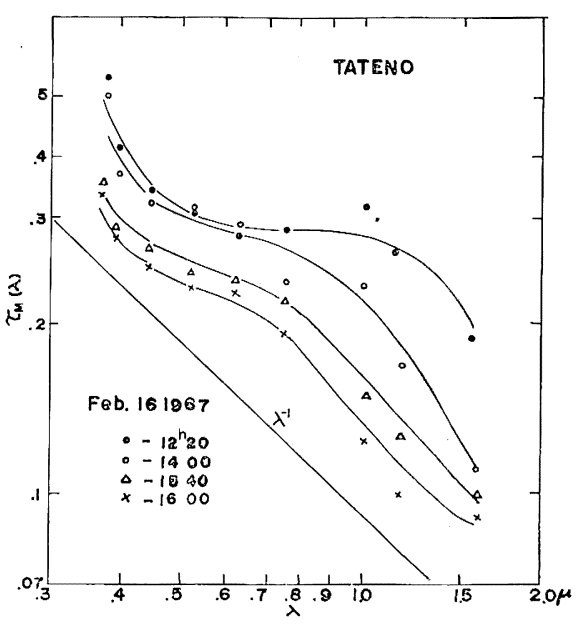

Fig. 11. Same as Fig. 10 but on the afternoon of Feb. 16. 


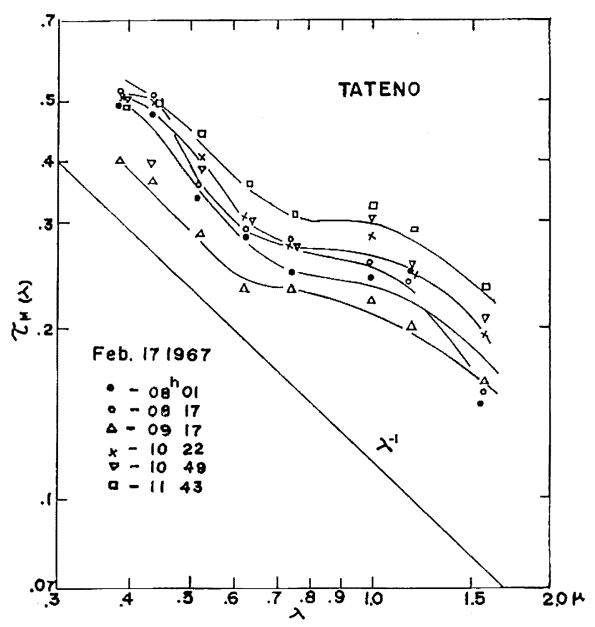

Fig. 12. Same as Fig. 10 but on the morning of Feb. 17.

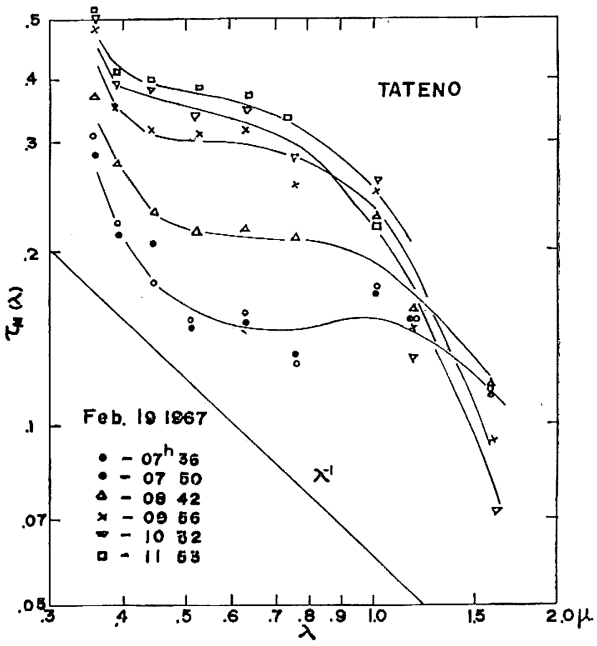

Fig. 13. Same as Fig. 10 but on the afternoon of Feb. 17.

The latter, indefinite curves, are generally characterized as follows: $\tau_{M}(\lambda)$ rapidly decreases with increasing wavelength in the short region, the slope of the curve gradually diminishes in the intermediate region and increases again in the IR region. In other words, it is characterized by a deviation from a mean line in a decreasing sense, which appears in a part of the short region and by a deviation from the mean line in increasing sense, which appears in the IR region. Some examples of this group are shown in Figs. 10 through 16. In these figures one might see that all curves show the characteristics mentioned above in their forms with some differences in detail. The range of wavelengths in which the deviations of curves appear varies widely

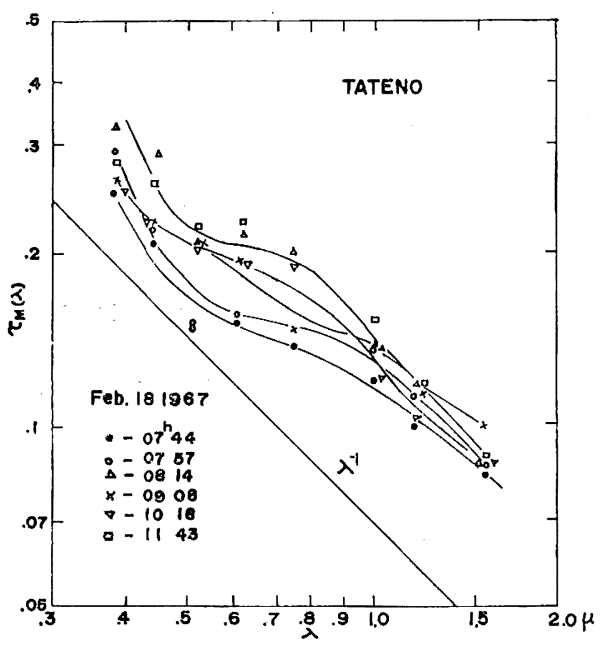

Fig. 14. Same as Fig. 10 but on the morning of Feb. 17.

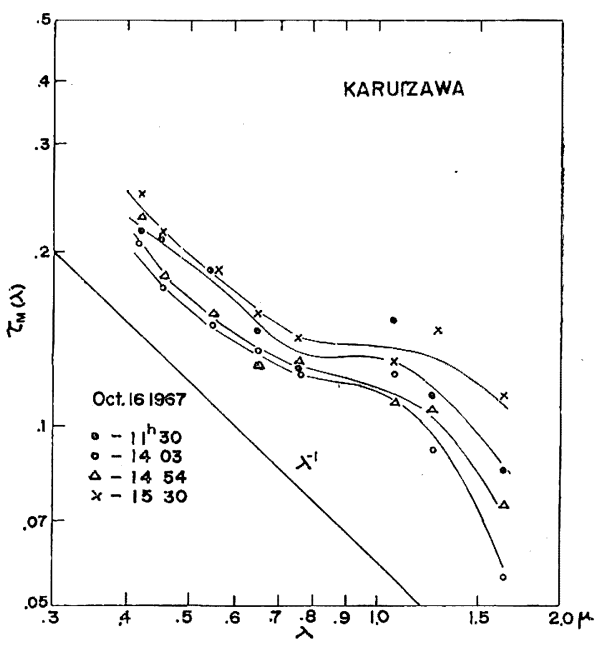

Fig. 15. Same as Fig. 10 but on the morning of Feb. 18. 


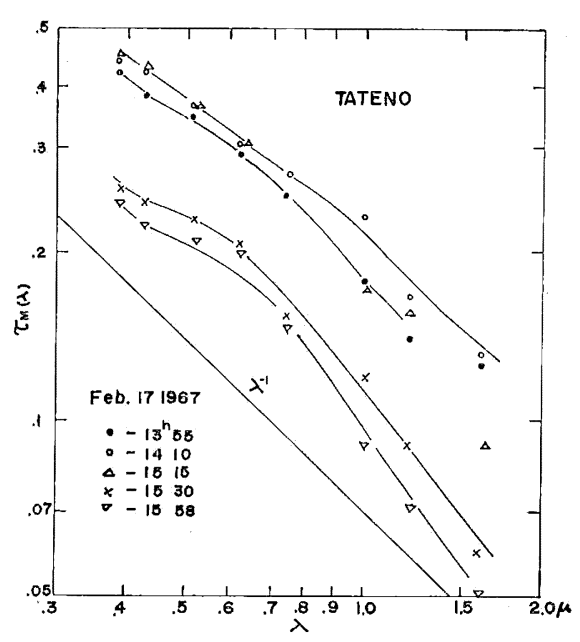

Fig. 16. Same as Fig. 10 but on at Karuizawa on Oct. 16.

from case to case. The distributions obtained on the same day generally resemble each other but there are some cases where remarkable changes occur in the distributions of $\tau_{M}(\lambda)$ within a short period. The results on Feb. 16 and 19 (Figs. 11 and 13) show rapid changes in the distribution. The curves for the morning (Fig. 10) have the same form of distribution but those obtained after $14 \mathrm{~h}$ (Fig. 11) are remarkably different from them. In Fig. 13 the distributions for early morning show different forms of distributions from the others.

\subsection{Spectral and angular distributions of aureole intensities}

The ratio $r(\lambda, \theta) / r_{0}(\lambda)$ represents the intensity of scattered radiation $I(\lambda, \theta)$ coming from the small sky area whose angular distance from the sun is $\theta$ towards the zenith, relative to the intensities of solar radiation outside the atmosphere $I_{0}(\lambda)$. About forty measurements are available for the analysis of spectral and angular distributions of aureole intensities.

Aureole intensities in the small angular distances $\left(\theta<5^{\circ}\right)$ increase with increasing wavelength and those in the larger angular distances $\left(\theta>10^{\circ}\right)$ very slowly increase or slowly decrease with increasing wavelength, especially in the IR region.

The relative intensities of aureole in the short region at Tateno for $\theta=1^{\circ}$ increase rapidly with increasing wavelength and their values appear in the range $1 \times 10^{-4}$ to $3 \times 10^{-4}$. In the intermediate region, the slopes of distributions generally decrease with increasing wavelength and the values of relative intensities are about $5 \times 10^{-4}$. In the IR region, the curves of distributions are flat and the values of relative intensities are about $8 \times 10^{-4}$. Examples of them are shown Fig. 17. In these figures one might see that the spectral distributions for larger angular distances $\left(\theta=10^{\circ}\right.$ or $\left.15^{\circ}\right)$ show a flat or slightly decreasing slope with increasing wavelength and that the values of relative intensities are about $5 \times 10^{-6}$.

The relative intensities of aureole measured at Karuizawa are generally smaller than those at Tateno. In the short region, they are $5 \times 10^{-5}$ to $1 \times 10^{-4}$ for $\theta=1^{\circ}$ and 
Fig. 17a. Spectral distributions of aureole intensities corresponding to Type I at Tateno on Feb. 18.
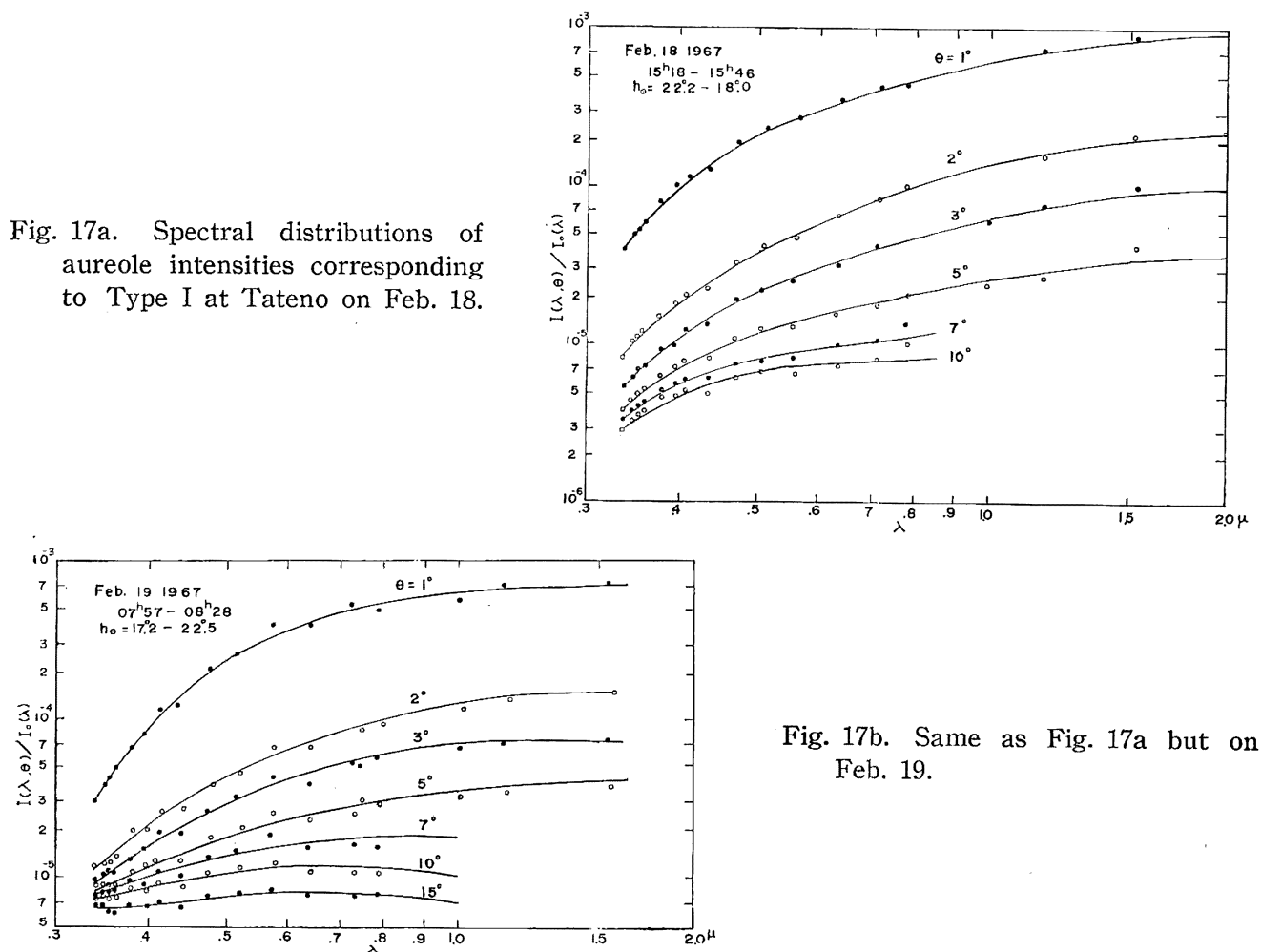

Fig. 17b. Same as Fig. 17a but on Feb. 19.

Fig. 18a. Same as Fig. 17a but at Karuizawa on Oct. 15.
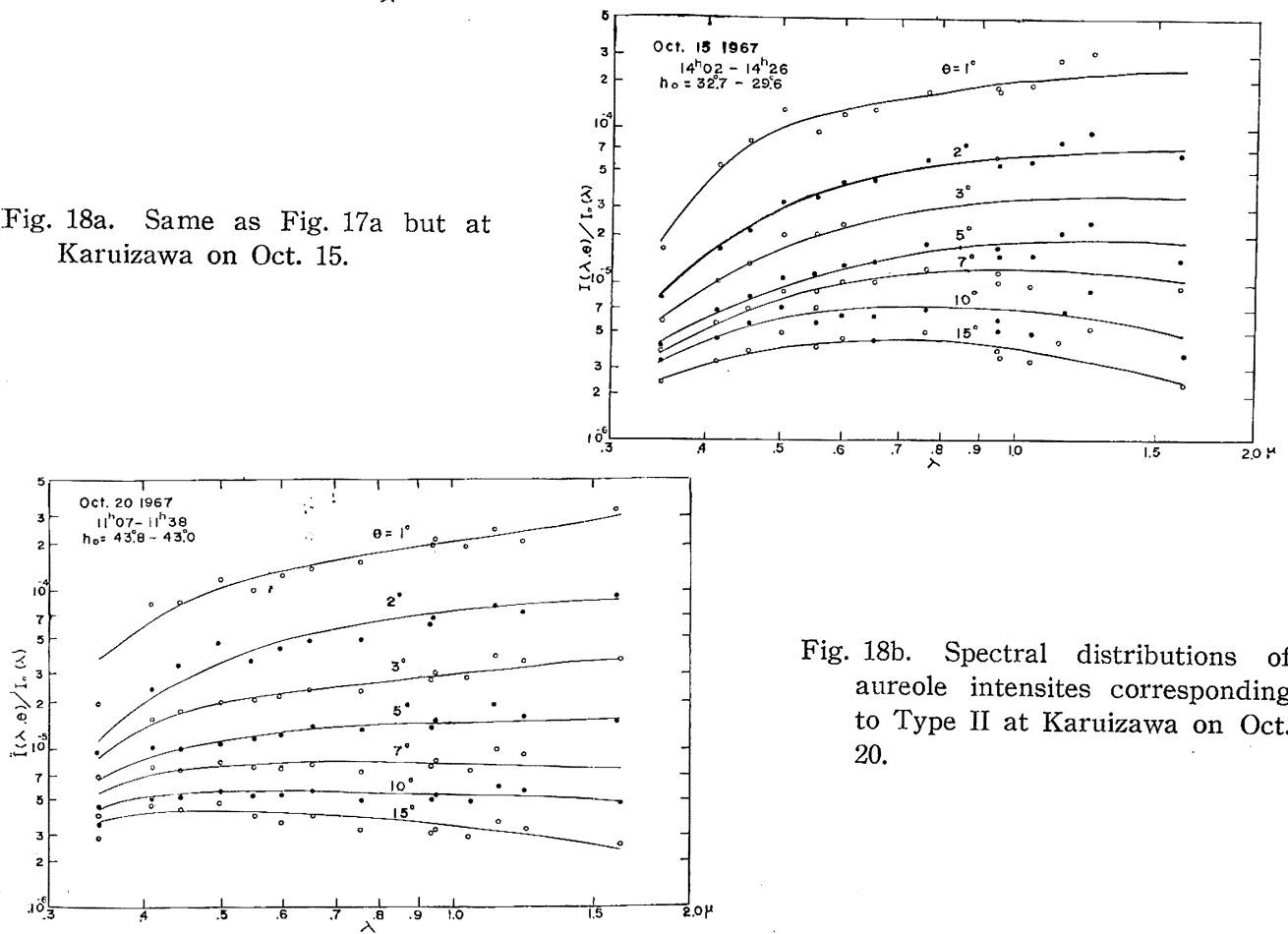

Fig. 18b. Spectral distributions of aureole intensites corresponding to Type II at Karuizawa on Oct. 20. 


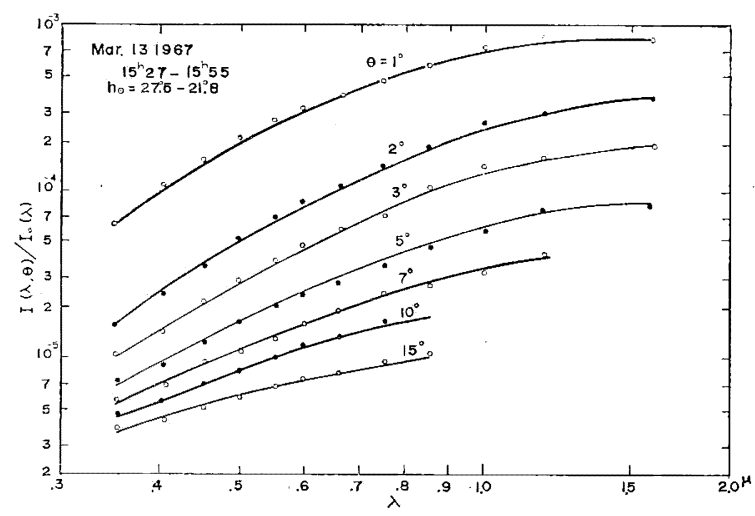

Fig. 19a. Spectral distributions of aureole intensities corresponding to Type III at Tokyo on Mar. 13.

Fig 19b. Same as Fig. 19a but on Dec. 23.
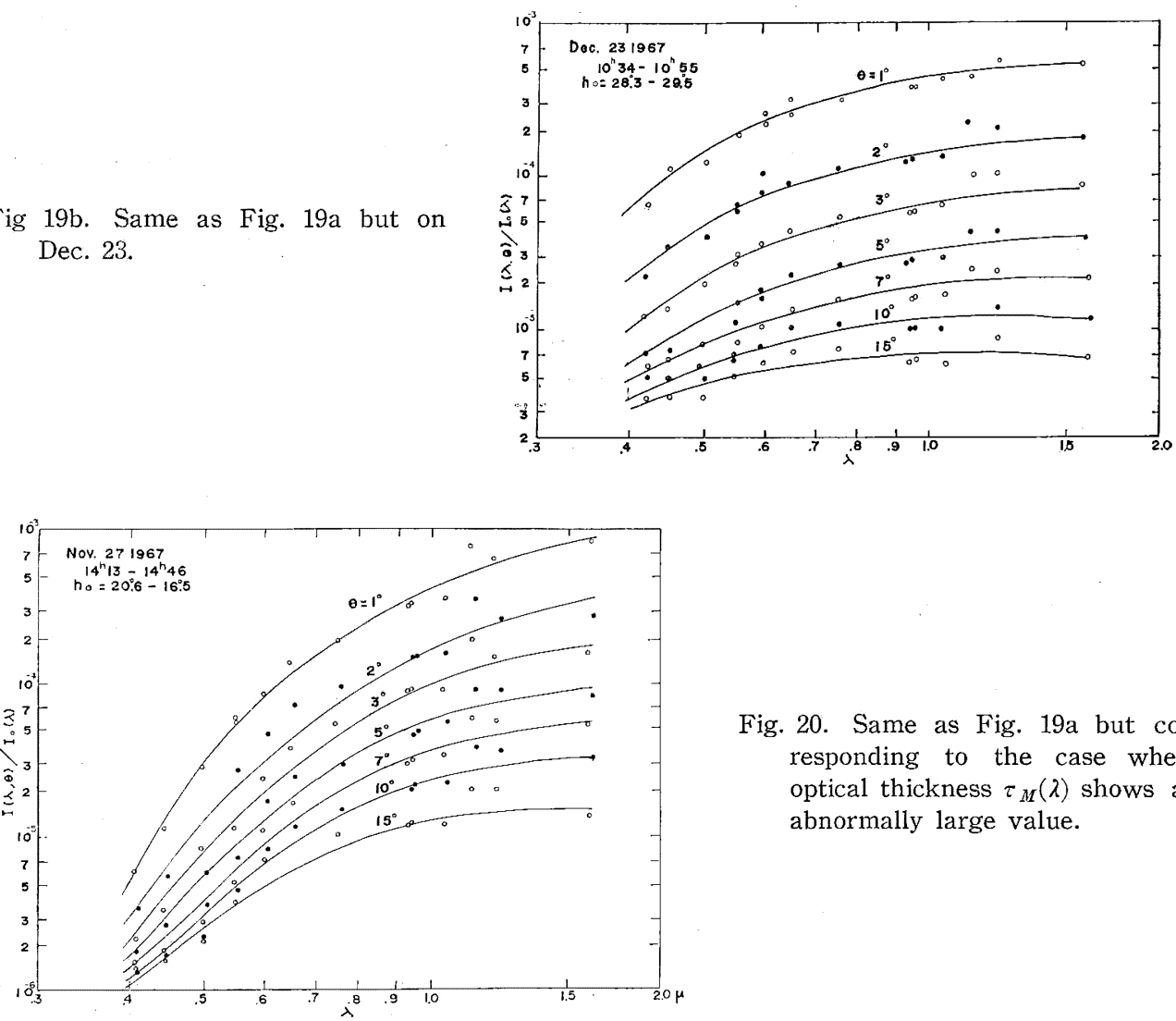

Fig. 20. Same as Fig. 19a but corresponding to the case where optical thickness $\tau_{M}(\lambda)$ shows an abnormally large value.

3 or $4 \times 10^{-6}$ for $\theta=15^{\circ}$, and the ratio of intensities at Karuizawa to those at Tateno for $\theta=1^{\circ}$ is about $1 / 2$ but about 0.8 for $\theta=15^{\circ}$. The slopes of distribution in the short region are smaller than those at Tateno and they gradually decrease with increasing wavelength. The values of relative intensities in the IR region are about 2 or $3 \times 10^{-4}$ for $\theta=1^{\circ}$ and about $5 \times 10^{-6}$ for $\theta=15^{\circ}$ which is nearly the same as those at Tateno. Some examples at Karuizawa are shown in Fig. 18. 
Fig. 21a. Spectral distributions of aureole intensities corresponding to Type I at Tateno on the morning of Feb. 18.
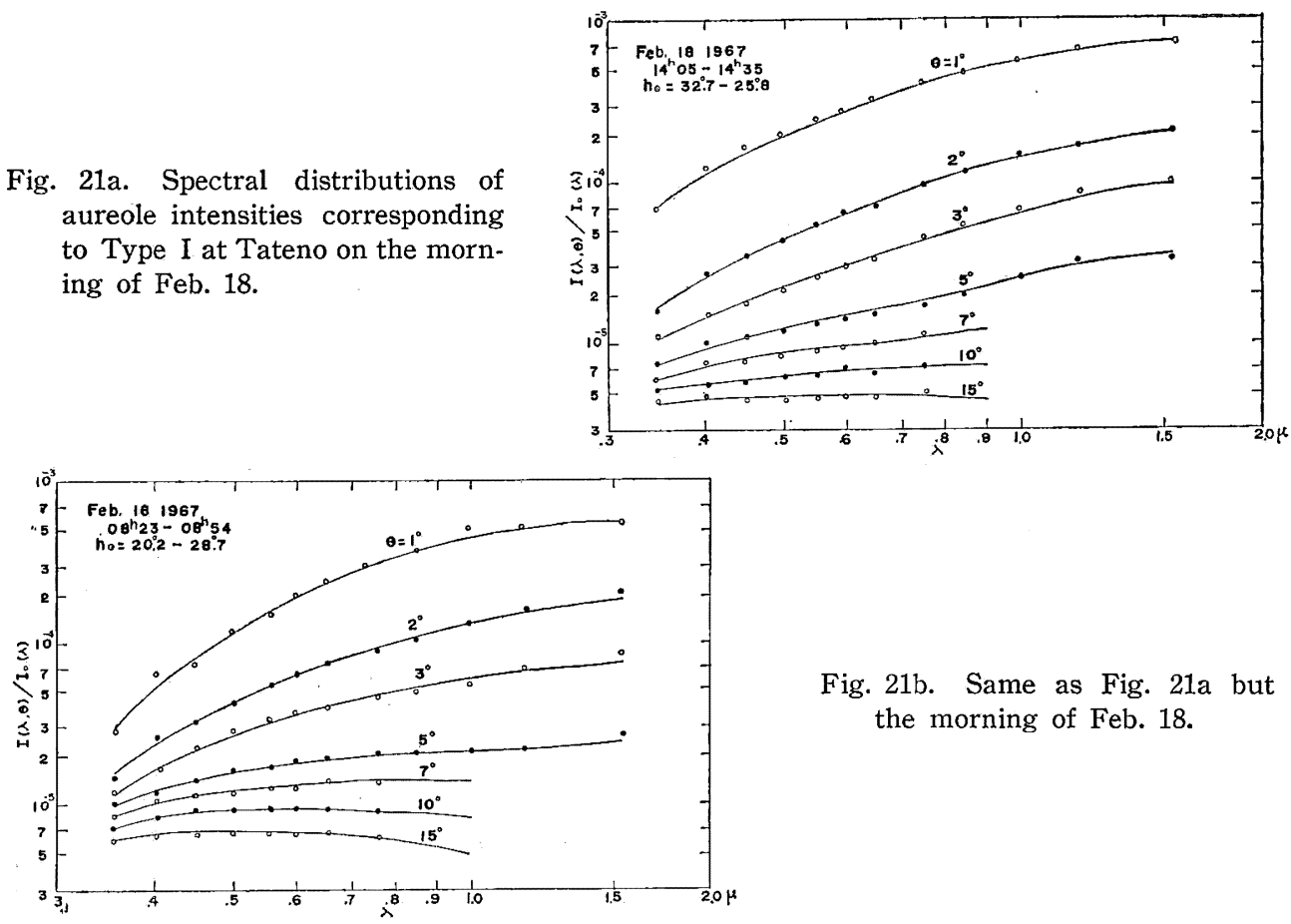

Fig. 21b. Same as Fig. 21a but in the morning of Feb. 18.

Fig. 22a. Spectral distributions of aureole intensities corresponding to Type II at Karuizawa on Oct. 20.

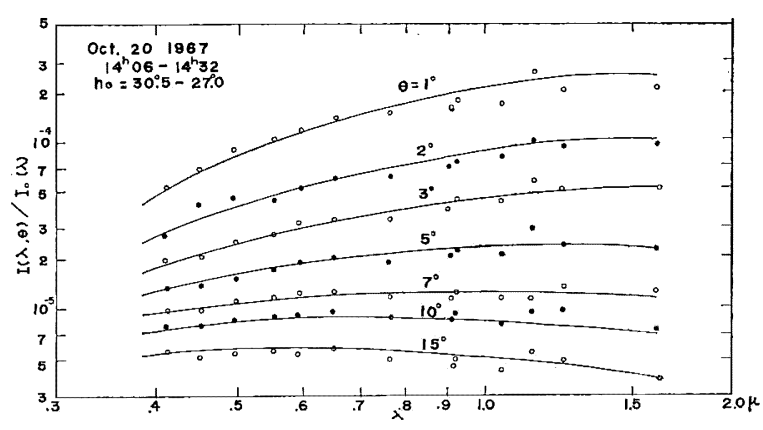

The values of relative intensities of aureole measured at Tokyo and their spectral distributions vary within a wide range. The spectral distribution curves in the short and intermediate regions for $\theta=1^{\circ}$ represent the slopes similar to those at Karuizawa but in the IR region the slopes of distribution are steeper than those at Karuizawa and Tateno. Some examples at Tokyo are shown in Fig. 19. In the case of abnormally large optical thickness in Tokyo, the relative intensities of the aureole in the short and the intermediate regions are very small and the slopes of spectral distributions are very steep. In the IR region, however, the relative intensities increase with increasing wavelength and reach to those of the normal case. This case is shown in Fig. 20 and the other samples for three stations are shown in Figs. 21 to 23.

From each measurement of aureole intensities we can obtain their angular distributions for any wavelength. Some examples of angular distributions are shown in Fig. 24 through 29. The angular distributions are described by the relative values for the 


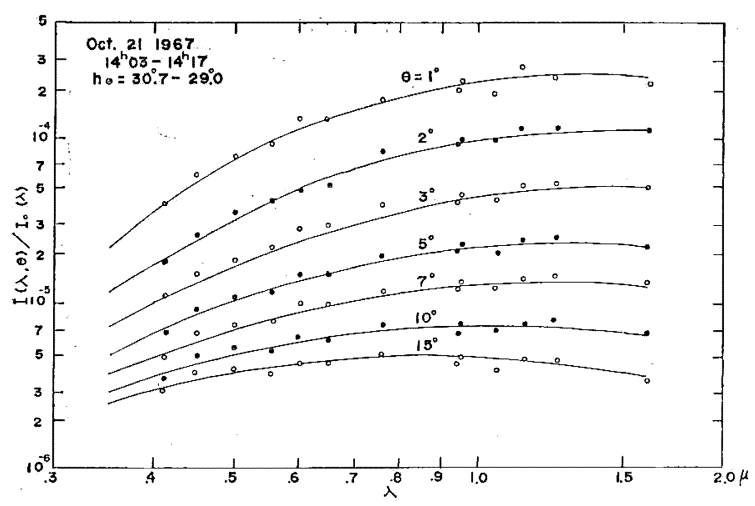

Fig. 22b. Same as Fig. 22a but on Oct. 21.

Fig. 23a. Spectral distributions of aureole intensities corresponding to Type III at Tokyo on Dec. 1 .
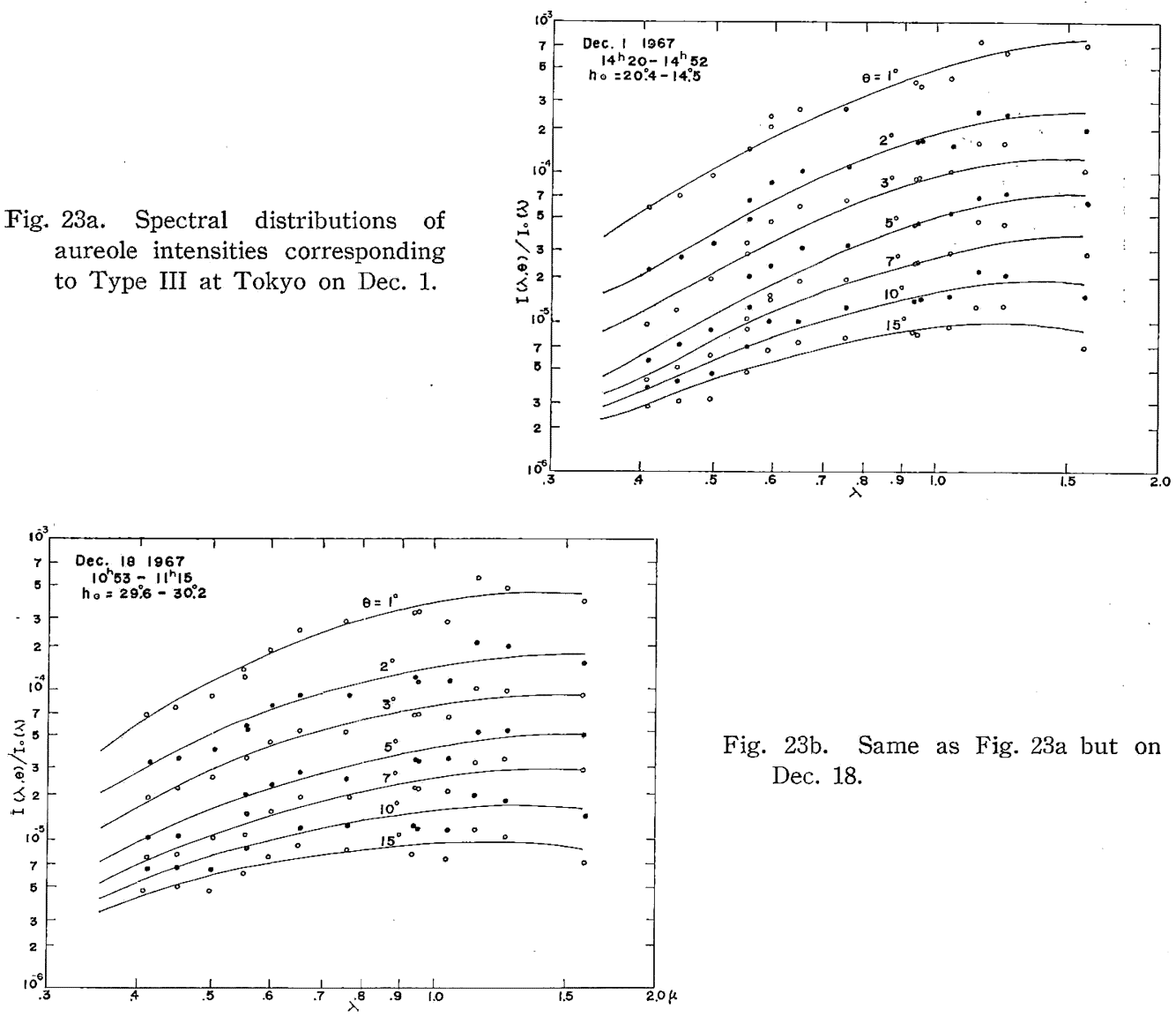

Fig. 23b. Same as Fig. 23a but on Dec. 18.

values of $\theta=1^{\circ}$. In these figures one might see that, as a general feature, slopes of the distribution curves increase with increasing wavelength and in the short region the slopes of curves diminish with increasing angular distances.

The intensities for $\theta=2^{\circ}$ are more variable in the short region than in the intermediate and IR regions and they are generally smaller at Tateno than at the other 


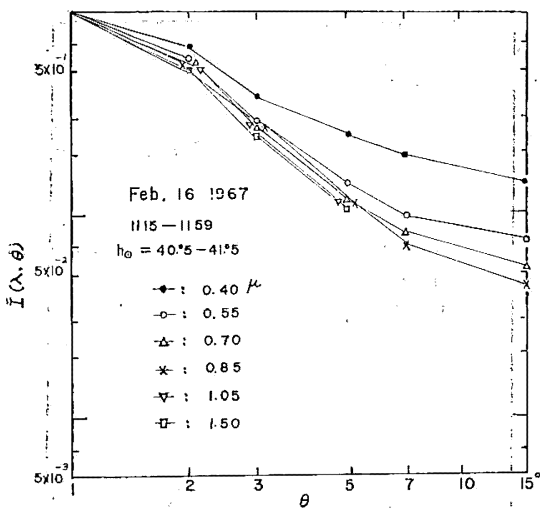

Fig. 24. Angular distribution of aureole intensity corresponding to Type I at Tateno. The aureole intensity at $\theta$ is represented by the relative value to that at $\theta=1^{\circ}$. The mark for each wavelength shown in this figure is used in the same way in all figures of angular distribution.

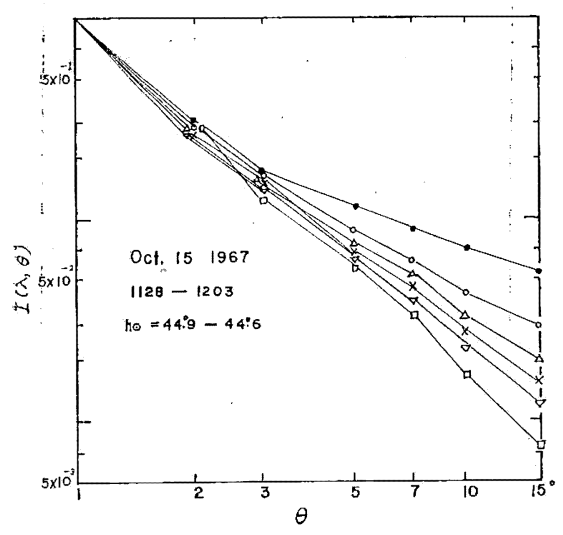

Fig. 26. Same as Fig. 24 but at Karuizawa on Oct. 15.

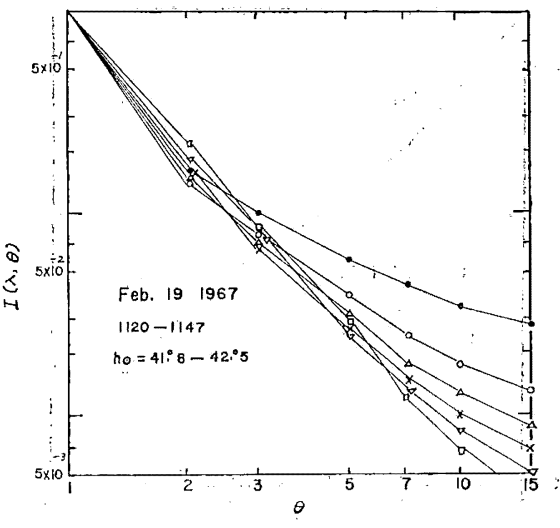

Fig. 25. Same as Fig. 24 but on Feb. 19.

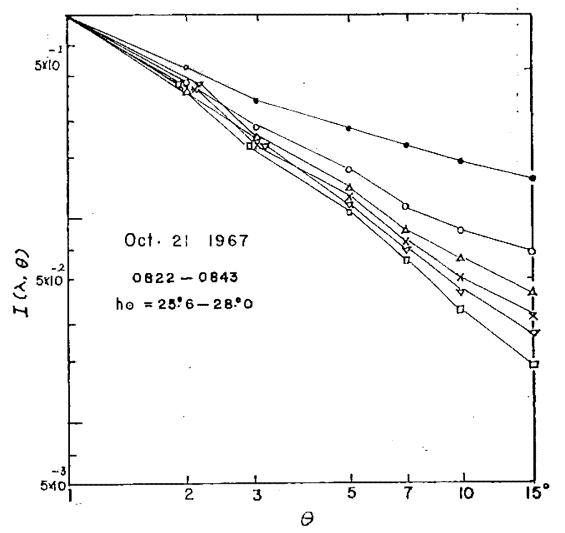

Fig. 27. Angular distribution of aureole intensity corresponding to Type II at Karuizawa on Oct. 21.

two stations on the average. The relative aureole intensities are in the range 0.2 to 0.6 and their dependencies on wavelength are very small in a single measurement. Aureole intensities in the range of angular distance $3^{\circ}$ to $5^{\circ}$ generally amount to onetenth of those for $\theta=1^{\circ}$. For large angles, the relative values in the short region obtained at Tateno are the smallest among the three stations and those of Karuizawa are the largest. In the short region, the values at Tateno are about 0.04 , those at Karuizawa vary from 0.06 to 0.15 and at Tokyo from 0.05 to 0.20 . In the intermediate region, they are 0.01 to 0.025 at Tateno, at Karuizawa 0.02 to 0.04 and at Tokyo 0.015 to 0.05 . In the IR region, they are 0.008 to 0.02 at Karuizawa and 0.015 to 0.02 at Tokyo. There are no measurements in the IR region for $\theta$ larger than $7 \mathrm{deg}$. at Tateno. 


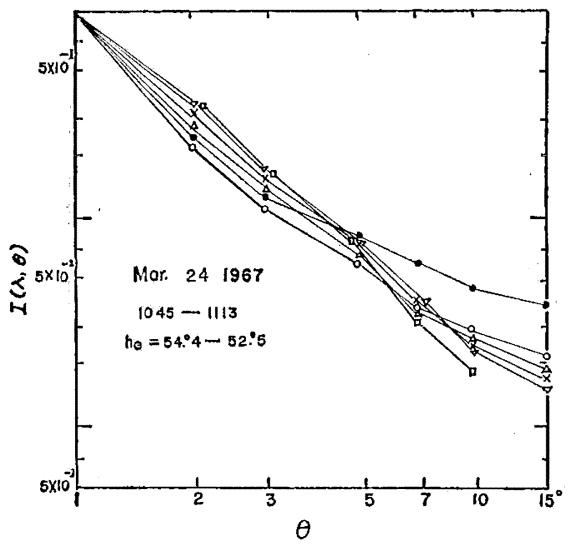

Fig. 28. Angular distribution of aureole intensity corresponding to Type III at Tokyo on Dec. 13.

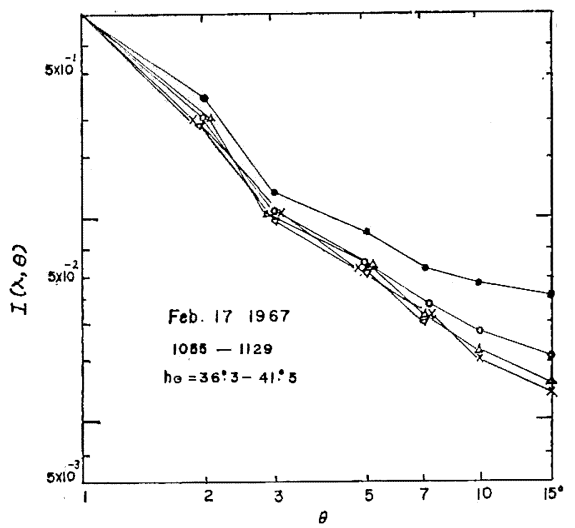

Fig. 30. Angular distribution of aureole intensity corresponding to Type $\mathrm{I}$ at Tateno on Feb. 17.

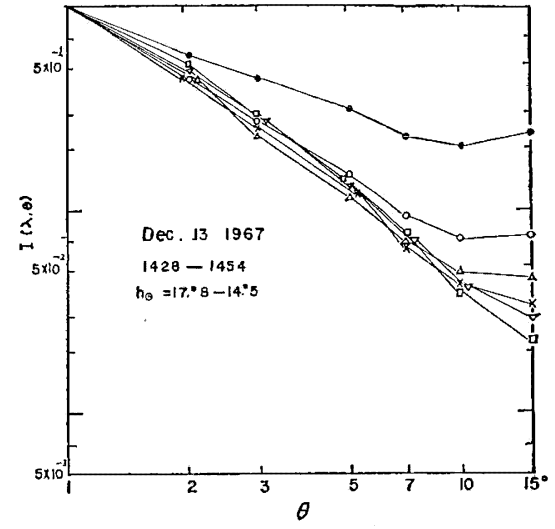

Fig. 29. Same as Fig. 28 but on Mar. 24.

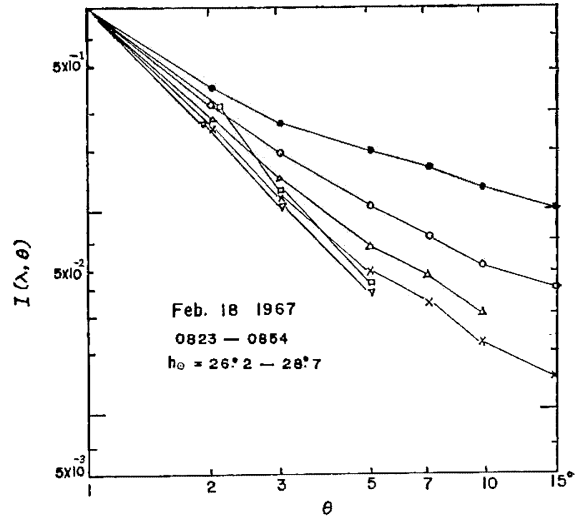

Fig. 31. Same as Fig. 30 but on Feb. 18.

In general, the slopes of angular distribution curves are largest at Tateno and are smallest at Karuizawa among the three stations. The angular distributions for Tokyo vary widely both in slope and in wavelength dependency. The classification of the results of angular distributions into some definite types is rather difficult. From the measurements described above, one might notice that some results show large dependency of the slope of the angular distributions of aureole intensities on wavelength and some results show very small dependency. These features are shown in Figs. 30 to 35 . 


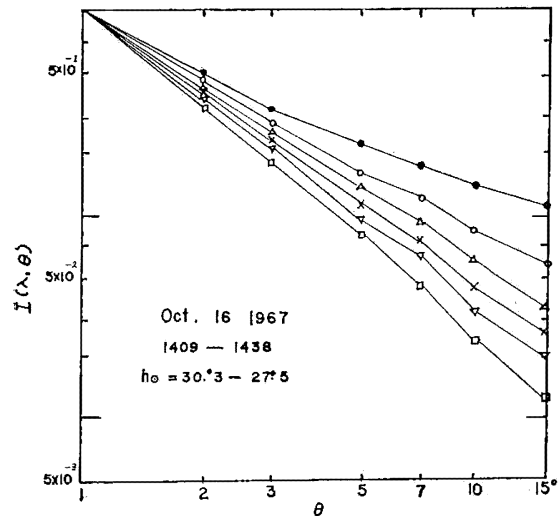

Fig. 32. Same as Fig. 30 but at Karuizawa on Oct. 16.

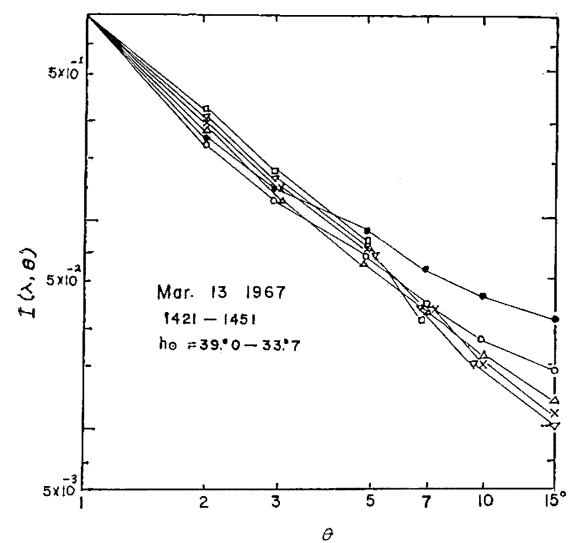

Fig. 34. Angular distribution of aureole intensity corresponding to Type III at Tokyo on Mar. 13.

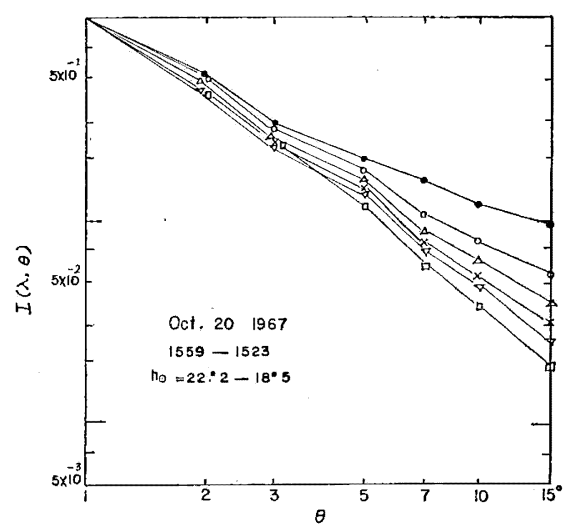

Fig. 33. Angular distribution of aureole intensity corresponding to Type II at Karuizawa on Oct. 20.

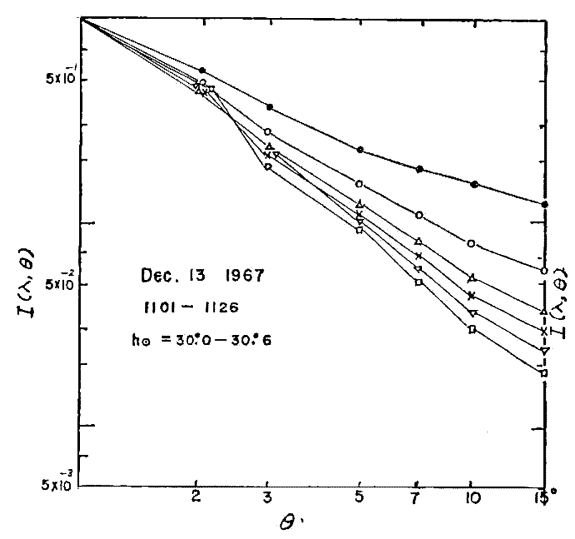

Fig. 35. Same as Fig. 34 but on Dec. 13.

\section{Discussion of Results}

\section{1 Spectral distributions of optical thickness}

\subsubsection{Comparison with earlier measurements}

As mentioned above, 14 wavelengths are selected to obtain the spectral distributions of optical thickness due to aerosol particles in the atmosphere. In the IR region, narrow window regions between two absorption bands of water vapour are selected.

For comparison with the results of measurements, the spectral distributions of $\tau_{M}(\lambda)$, which were deduced by FoITZIK $(1965)$ and DEIRMENDJIAN $(1959,1960)$ on the basis of the results of the Smithsonian Institution, are shown in Figs. 36 and 37. In the results shown in Fig. 36b, the average slope of distribution is larger than that of the curve of $\lambda^{-1}$ but smaller than that of $\lambda^{-2}$. In the intermediate region, there are 


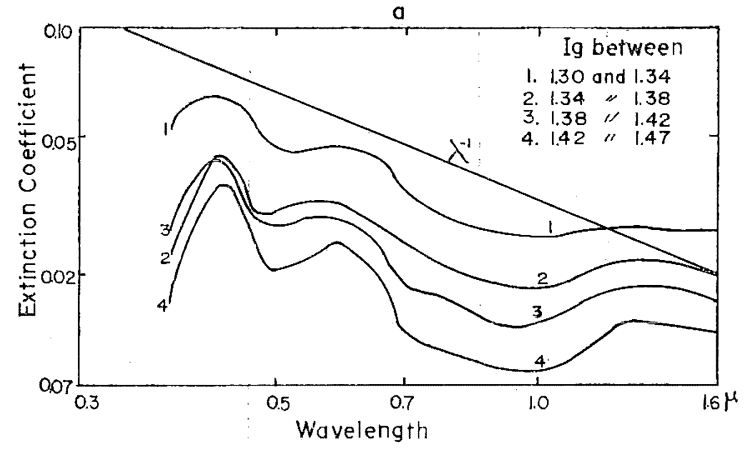

Fig. 36a. Spectral distributions of extinction coefficients deduced by FoITzIK (1965) from the observations of the Smithsonian Institution. $\mathrm{I}_{g}$ is the total solar radiation at the air mass 2.0 and ppw is the precipitable water vapour in the atmosphere.

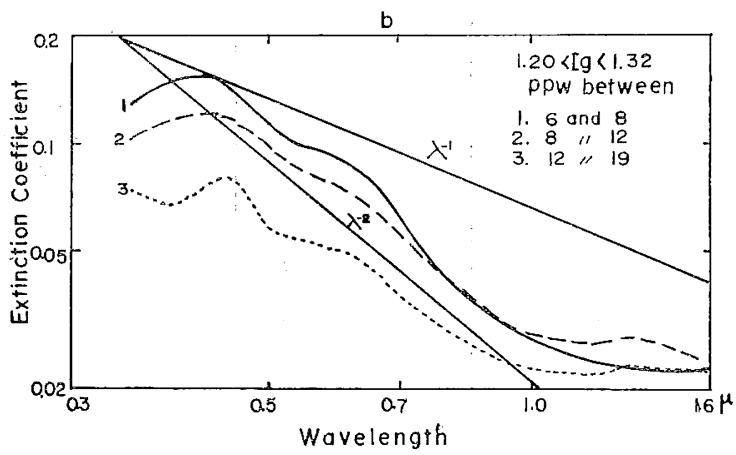

Fig. 36b. Same as Fig. 36a but for different values of ppw.

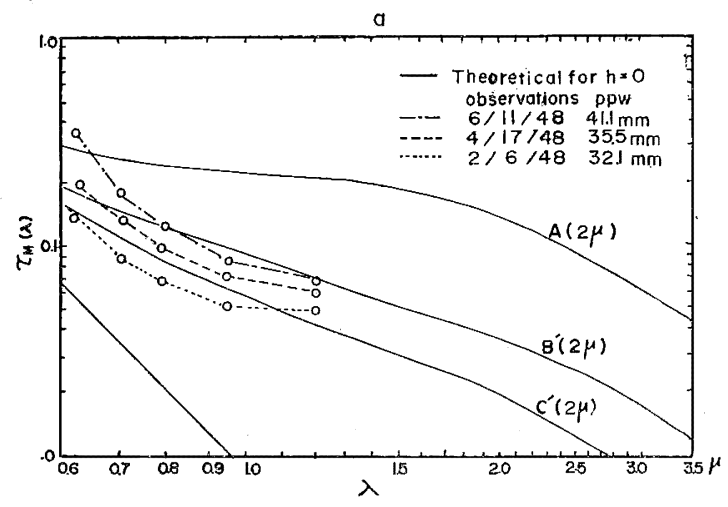

Fig. 37a. Spectral distributions of $\tau_{M}(\lambda)$ at sea level. The smooth curves are the distributions of $\tau_{M}(\lambda)$ calculated by DEIRMENDJIAN. The open dots connected by broken lines represent the distributions of $\tau_{M}(\lambda)$ deduced by DEIRMENDJIAN from the observations at the Smithsonian Astrophysical Observatory. 


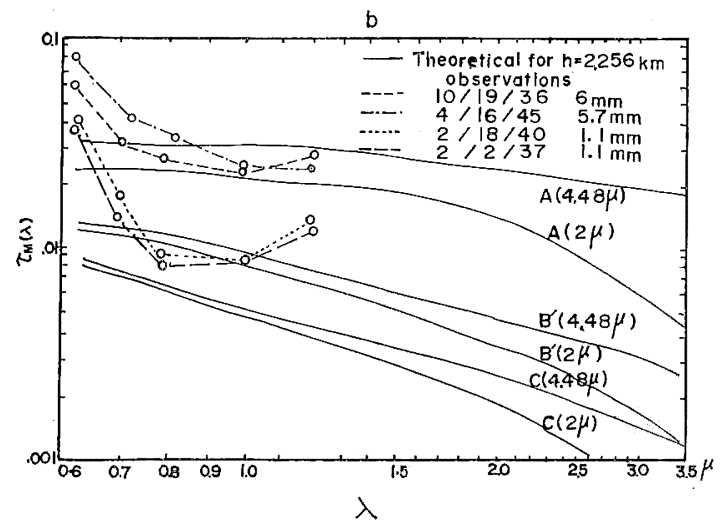

Fig. 37b. Same as Fig. 37a but at the level of $2.256 \mathrm{~km}$.

hollows and humps of the curve and in the short region, $\tau_{M}(\lambda)$ decreases with decreasing wavelength. In the IR region, the slopes of curves decrease again and become smaller than that of $\lambda^{-1}$. A comparison of these results with those of the author's measurements shows fairly good agreements in distributions in the intermediate region but an appreciable difference in the short region. In the short region, the results of the Smithsonian Institution show abnormally small optical thickness. In Fig. 36a, the curves show a hump in the region around $1.5 \mu$ but those of the author's measurements generally show a very small hump in the region around $1.0 \mu$. The results obtained at Karuizawa on Oct. 20 and 21 show some degree of agreements of distributions with those of Fig. 36b in the IR region, as shown in Figs. 38 and 39.

DEIRMENDJIAN deduced the spectral optical thickness shown in Fig. 37 from the observations at the Smithsonian Astrophysical Observatory (ALDRICH and HOOVER, 1954) for comparison with his calculation. The measured distribution curves in Fig.

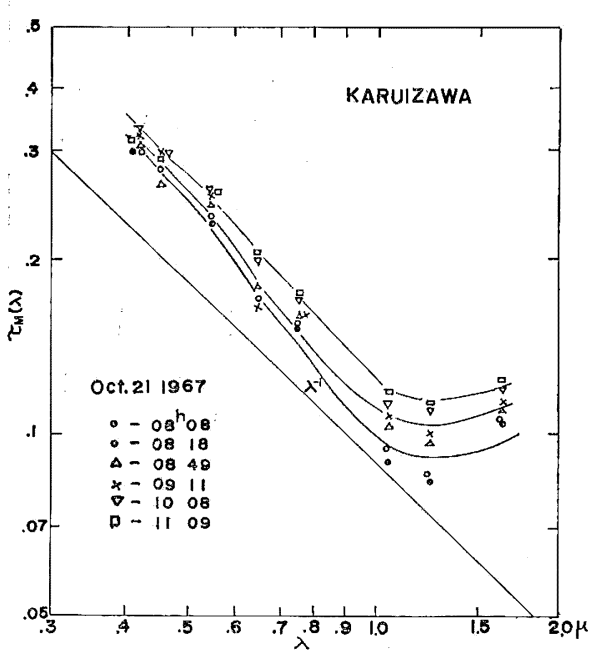

Fig. 38. Spectral distributions of $\tau_{M}(\lambda)$ of Type II at Karuizawa on Oct. 21.

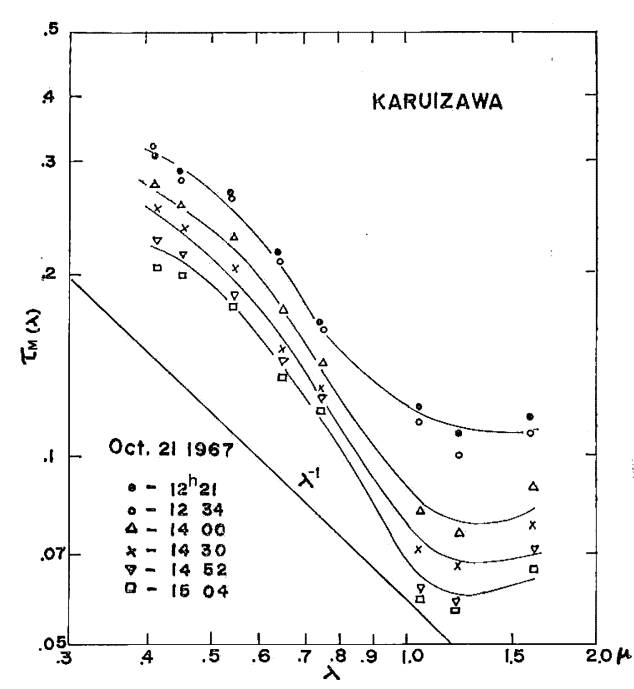

Fig. 39. Same as Fig. 38 but on the afternoon of Oct. 21 . 


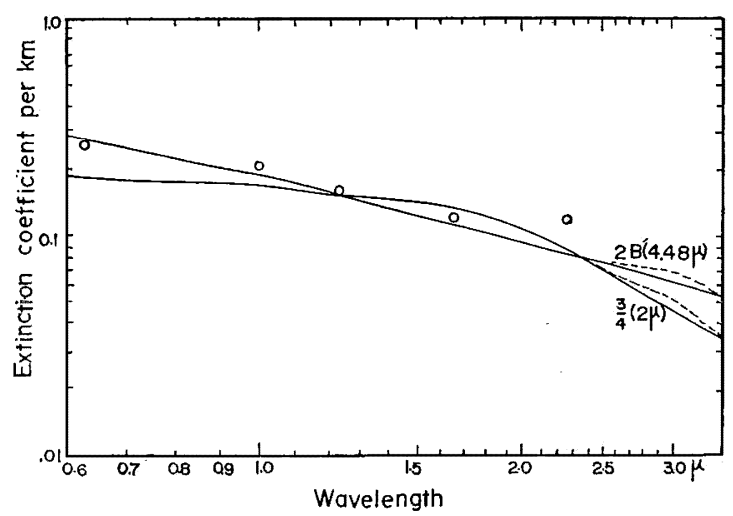

Fig. 40. Horizontal attenuation coefficient at sea level calculated by DEIRMENDJIAN (smooth curves) and that measured by GeBbIE et al. (open dots).

37 show steep slopes in the intermediate region, quite different from the author's distributions. If we consider the effect of absorption by ozone (DEIRMENDJIAN, 1959) the slopes of curves are still much larger than the author's. As described above, the

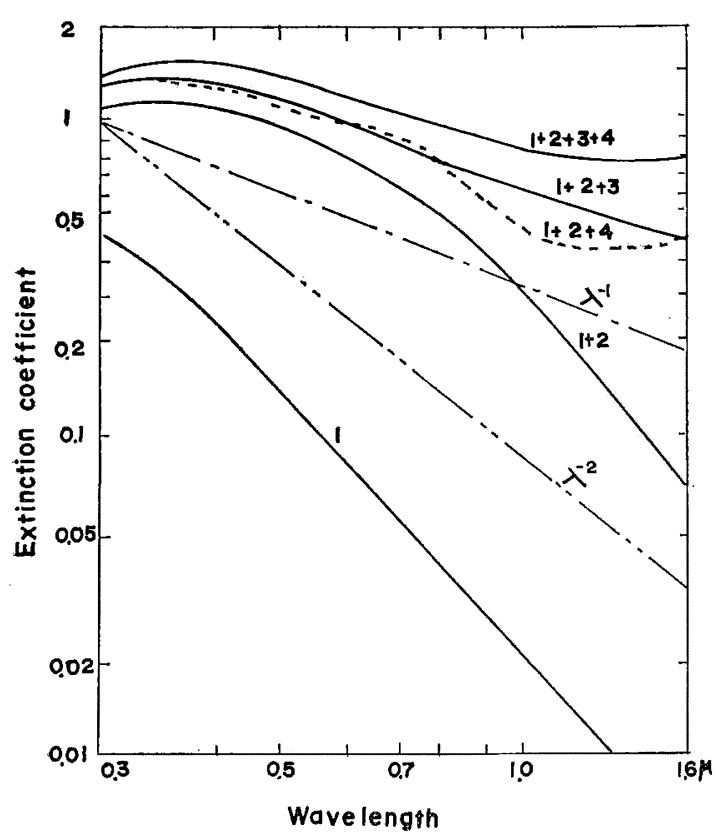

a

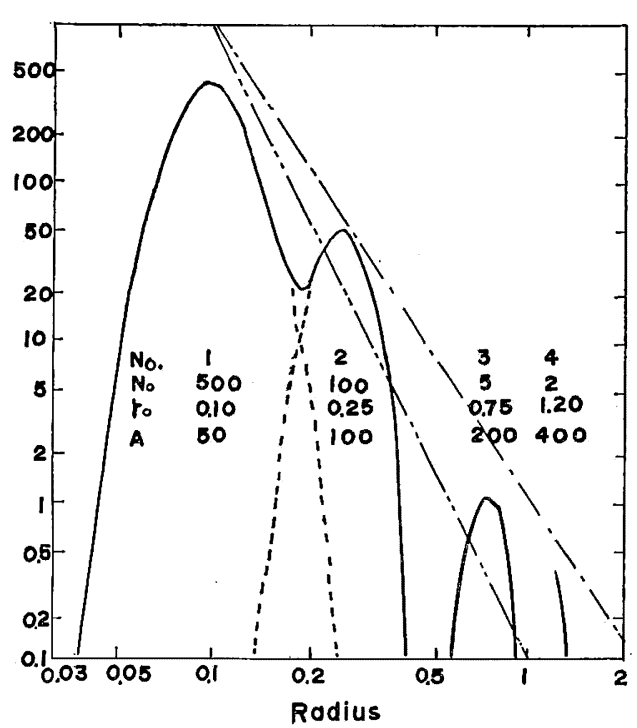

b

Fig. 41. a) Models of the Gaussian group assumed by FoITZIK in his calculation and b) Spectral distributions of extinction coefficients corresponding to the combinations of the Gaussian groups calculated by FolTzik. $N_{0}$ is the number of particles, $r_{0}$ the most frequent radius of the group and $A$ is the steepness of the Gaussian curve. 


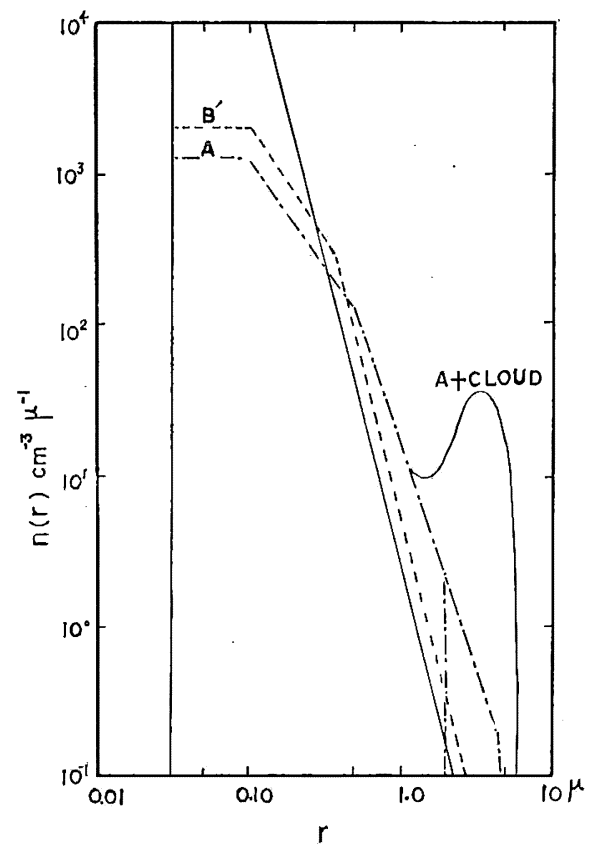

Fig. 42. Size distributions of aerosol particles employed by DerRMENDJIAN in his calculation.

spectral distribution curves of optical thickness deduced from the observations at the Smithsonian Institution are generally different in their form from the author's especially in the short region.

GEBBIE et al. (1953) measured the horizontal infrared transmission along the eastern coast of Scotland with a transmissometer and DEIRMENDJIAN computed the attenuation coefficient based upon these data. The result is shown with open dots in Fig. 40. The mean slope of the spectral distribution of $\tau_{M}(\lambda)$ in this figure can be approximately represented by $\lambda^{-1}$.

\subsubsection{Theoretical investigations by FoITZIK and DEIRMENDJIAN}

FoITZIK calculated the extinction coefficients corresponding to the size distribution represented by Gaussian groups in the wavelength region 0.3 to $1.6 \mu$. The results and the Gaussian groups are shown in Fig. 41. The spectral distributions of $\tau_{M}(\lambda)$ calculated by DEIRMENDJIAN corresponding to the combinations of power law size disbutions of particles are shown in Figs. 37 and 40. The size distributions of particles used for the computation by DEIRMENDJIAN are represented by curves $\mathrm{A}, \mathrm{B}^{\prime}$ and $\mathrm{C}$ in Fig. 42. The figures noted in the parentheses for each curve of Figs. 37 and 40 denote the maximum size of particles for each distribution. In a recent investigation, DEIRMENDJIAN (1964) defined a general formula for the size distribution of particles applicable even to the cloud model as follows;

$$
\dot{n}(r)=C r^{\nu} \exp \left(-b r^{r}\right)
$$

where $C, \nu, b$ and $\gamma$ are positive constants. The constants $C$ and $b$ are determined 
by the total number of particles and the critical radius $r_{c}$, assuming appropriate values of $\nu$ and $\gamma$. The spectral distributions of volume extinction coefficients calculated and the size distributions assumed by DEIRMENDJIAN are shown in Fig. 43. In the figures

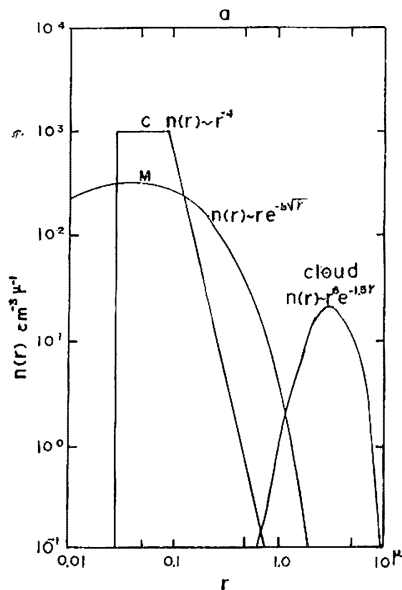

a

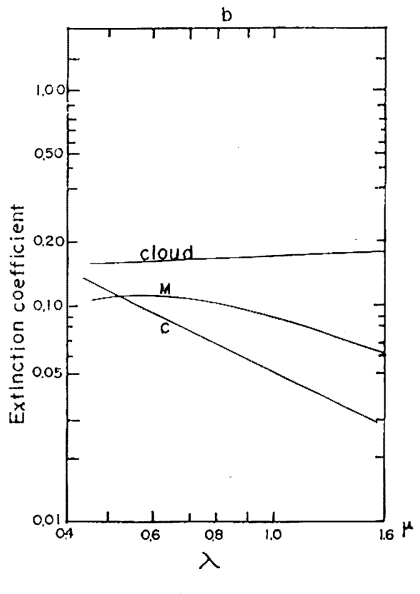

$\mathrm{b}$

Fig. 43. a) Size distributions of aerosol particles assumed by DEIRMENDJIAN in his calculation and b) Spectral distributions of volume extinction coefficients calculated by DEIRMENDJiAN.

shown above, we can recognize differences of spectral distributions of optical thickness due to differences of the size distributions of particles. From a comparison of the curve $1+2+3+4$ with the curve $1+2+3$ in Fig. 41 , for example, we can deduce the contribution of the Gaussian group 3 to the spectral distribution. That is, the deficit of particles in the region of radius 0.5 to $1.0 \mu$ causes a hollow of curve of optical thickness in the range of $\lambda 1.0$ to $16 \mu$. And the optical thickness due to the Gausian group 3 which lies in the range $r 0.5$ to $1.0 \mu$ is very effective in the IR region to produce the distribution curve $1+2+3$. The Gaussian group 4 which lies in the range $r 1.0$ to $1.5 \mu$ is considered to cause a hump in the curve in the wavelength range larger than $1.6 \mu$, although no calculated values in this range are indicated in the figure. In Fig. 37b, one can see the effect of the increase of the upper limit of the radius of particles upon the spectral distribution of $\tau_{M}(\lambda)$. The effect due to the increase of the upper limit of the radius from $2.0 \mu$ to $4.48 \mu$ is appreciable in the region of wavelengths larger than $2.0 \mu$.

\subsubsection{Comparison with theoretical investigations}

By a comparison of the results of the measurements with the theoretical results, we can infer the size distributions of aerosol particles taking into account the above mentioned relations between the size distributions and the spectral distributions of optical thickness.

The spectral distributions of $\tau_{M}(\lambda)$ measured are classified into the following three types ;

Type I A smooth curve with a hollow in the short or in the shorter side of the intermediate region and with a hump in the IR region. 
Type II A smooth curve with a hump in the short region and a hollow in the IR region.

Type III Almost linear but its slope gradually decreases in the IR region.

Discussion of Type I All the results obtained at Tateno and those obtained at Karuizawa on the afternoon of Oct. 15 belong to this type. The examples of this type are shown in Fig. 10 through 16.

Although the distribution of $\tau_{M}(\lambda)$ of this type is steeper in the short region than those calculated, the distributions in the intermediate and the IR region agree with those of calculation. The distributions in Fig. 10 and the curve $\mathrm{A}(2.0)$ or $\mathrm{A}(4.48)$ in Fig. 37 show good agreement with each other in the region 0.6 to $1.6 \mu$ in wavelength. The curves in Figs. 11,13 and 14 coincide with the curves $B^{\prime}(2.0)$ or $B^{\prime}(4.48)$ in Fig. 37. The distribution curves in Fig. 12 are characterized by a hollow in the curve in the intermediate region and a hump in the curve in the IR region. Looking at the curve $1+2+4$ in Fig. 41, one might see that the hollow and the hump in the curve appear in the region of wavelengths larger than that which corresponds to the hollow and hump obtained in the measurements. In the measured distribution curves we can find the hollow in the shorter side of the intermediate region and this is not so clear as that of the curve $1+2+4$ in Fig. 41 . The hollow in the curve appearing in the intermediate region in the author's results suggests that the number of particles in the range of radius about $0.1<r<0.5 \mu$ is smaller than that of the mean power law size distribution corresponding to the measured spectral distribution of $\tau_{M}(\lambda)$.

From the features of the spectral distribution of this type in the short region, which is steeper than was calculated, we can infer that the number of particles smaller than $0.1 \mu$ in radius is considerably larger than that of the Gaussian group 1 in Fig. 41 or that of Model A or B' in Fig. 42.

From the considerations described above, we can deduce a mean size distribution of particles corresponding to Type $I$, that is, the power law size distribution with a rather steep slope in the range $r<0.1 \mu$, a hollow in the range $0.1<r<0.5 \mu$ and a hump in the range $0.5<r<1.0 \mu$. In other words, the spectral distribution of optical thickness may be reproduced in the consideration of the size distribution of particles which is a deformation of the distribution of Model $\mathrm{A}$ or $\mathrm{B}^{\prime}$ in Fig. 42 or Model $\mathrm{M}$ in Fig. 43. The hollow and the hump which deform the curve of Model $\mathrm{A}, \mathrm{B}^{\prime}$ or $\mathrm{M}$ in the appropriate regions of radius reproduce the hollow and the hump in the curve of the spectral distribution of optical thickness appearing in the results of measurements.

Discussion of Type II The results falling into this type were obtained at Karuizawa on Oct. 20 and 21. Some examples are shown in Figs. 38 and 39. This type shows the agreement with the curve $1+2$ in Fig. 41 in the short and the intermediate region. In the IR region, the measured distribution shows a hollow in the curve and then the distribution in the whole range of wavelengths show fairly good agreement with the curve $1+2+4$ in Fig. 41 but the hollow in the meassured curve in the IR region is not so sharp as that of the curve $1+2+4$. From this fact we can deduce the size distribution of particles as the combination of four Gaussian groups with a slight decrease in the number of particles in the Gaussian group 3 in Fig. 41. 
Discussion of Type III The results belonging to this type were obtained at Tokyo and Karuizawa. The examples of this type are shown in Figs. 8 and 9. The measured values at Tokyo show considerable differences from those of the other two stations in the magnitude of optical thickness. The curve of the distribution of $\tau_{M}(\lambda)$ of this type is almost linear in the short and the intermediate region, whose slope lies between the slope of $\lambda^{-1}$ and that of $\lambda^{-2}$ and in the IR region slightly smaller than the former (Fig. 9).

The distribution of this type in the short and the intermediate region is approximately reproduced by the combination of a power law size distribution and the Gaussian group 4 in Fig. 41 whose contribution was estimated as the difference between the curve $1+2+3+4$ and the curve $1+2+3$ in the figure. But the contribution of the Gaussian group 4 is too large to reproduce the distribution in the IR region. For example, if we add the component of $\tau_{M}(\lambda)$ corresponding to the Gausian group 4 to the curve of $\lambda^{-1}$ or $\lambda^{-2}$, we can nearly reproduce the distribution of this type in the short and the intermediate region, but the value of $\tau_{M}(\lambda)$ in the IR region is too large as compared with that of the measurements.

From these considerations, one might infer that the size distribution of the particles corresponding to this type is nearly a power law size distribution $\left(n(r) \sim r^{-3}\right.$ or $r^{-4}$ ) from which appears a slight increase of the number of particles larger than $1.0 \mu$ in radius.

From these features of the size distributions of particles for the three types of the spectral distributions of $\tau_{M}(\lambda)$ we can conclude that there are few cases of the pure power law distribution of particles and most of the measured spectral distributions of $\tau_{M}(\lambda)$ may be reproduced by the smooth curves with a hollow in the shorter side and a hump in the longer side of the radius range in the size distribution.

It is difficult to detect an upper limit to the radius of the particle in the sizes distribution from the measurements performed at the three stations, because the apparent differences of the spectral distribution of $\tau_{M}(\lambda)$ corresponding to the change of the upper limit of the radius from $2.0 \mu$ to $4.48 \mu$ occur in the range larger than $2.0 \mu$ in wavelength in Fig. 37b.

For the inference of the size distribution of particles we must assume the value of the refractive index of particles. In general, atmospheric aerosol particles are coated with a thin water or solution film whose refractive index $n$ is 1.30 to 1.50 . Since the value of the refractive index remarkably varies with wavelength in the range $\lambda>2.0 \mu$ (DEIRMENDJIAN, 1959), the effect of the variation of the refractive index with wavelength may not appear in measurements which cover wavelengths smaller than $2.0 \mu$ in wavelength.

The shape of the aerosol particle is also effective upon the scattering cross section, but it is shown by RosE (1952) that there is no difference of cross section between the rough sand particle and the spherical particle. Therefore, we can neglect the effect of the shape of the particle in this discussion.

\subsection{Spectral distributions of aureole intensities}

The measured aureole intensities described in Figs. 17 to 23 show the values considerably larger than those of the Rayleigh atmosphere. The ratio of the measured 


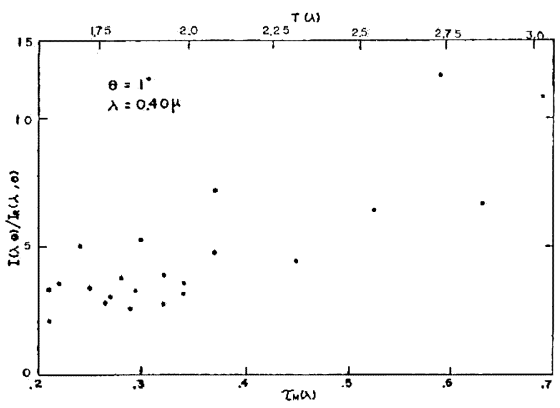

a

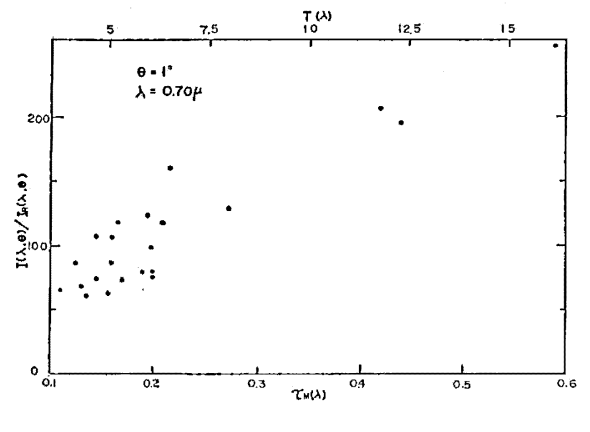

c

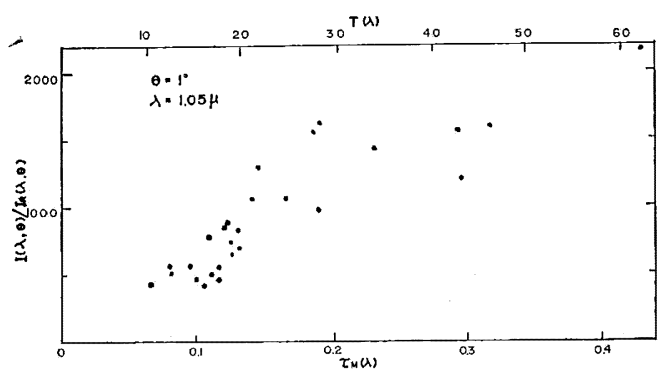

e

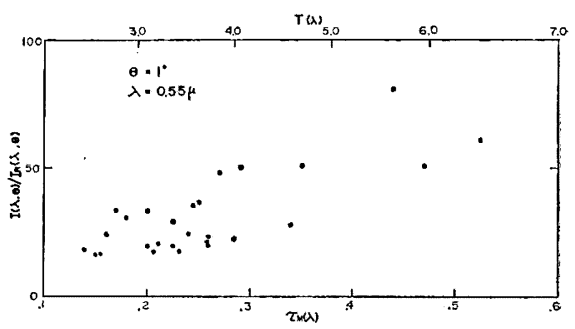

b

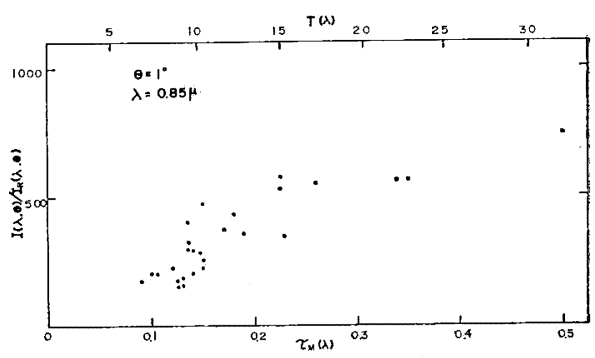

d

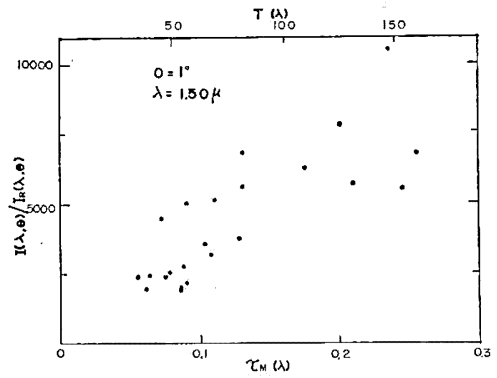

$\mathrm{f}$

Fig. $44 \mathrm{a}$ to $\mathrm{f}$. Relation between the ratio of aureole intensity to that for the Rayleigh atmosphere and optical thickness $\tau_{M}(\lambda)$ or turbidity factor $T(\lambda)$ for several wavelengths at $\theta=1^{\circ}$.

aureole intensity to that of the Rayleigh atmosphere, $R(\lambda, \theta)=I(\lambda, \theta) / I_{R}(\lambda, \theta)$ depends on the wavelength and the angular distance from the sun. $I_{R}(\lambda, \theta)$ is the intensity of scattered radiation in the Rayleigh atmosphere. $R(\lambda, \theta)$ is generally smaller than 10 in the short region and of the order of $10^{2}$ and $10^{3}$ in the intermediate and in the IR region respectively. This quantity is dependent on the optical thickness $\tau_{M}(\lambda)$ or the turbidity factor $T(\lambda)=\left[\tau_{M}(\lambda)+\tau_{R}(\lambda)\right] / \tau_{R}(\lambda)$, and $R(\lambda, \theta)$ increases with increasing $\tau_{M}(\lambda)$ or $T(\lambda)$. Correlations between $R(\lambda, \theta)$ and $\tau_{M}(\lambda)$ or $T(\lambda)$ are shown in Figs. 44 to 46. In these figures, the results obtained at various solar altitudes and for various atmospheric conditions are plotted in the same figures. Although the plots scatter over a 

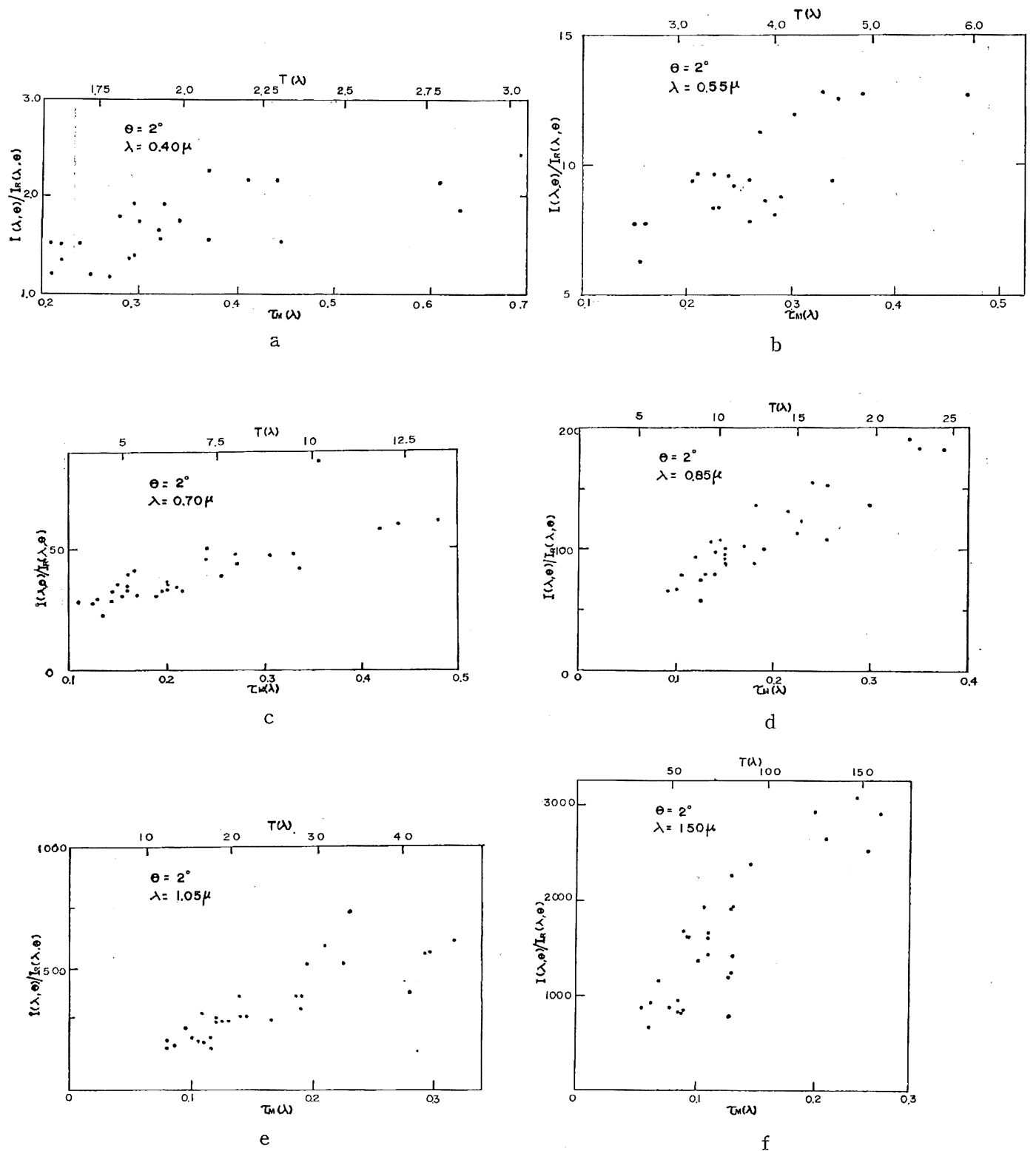

Fig. $45 \mathrm{a}$ to f. Same as Fig. $44 \mathrm{a}$ to $\mathrm{f}$ but for $\theta=2^{\circ}$.

Table 3. Mean increment of $R(\lambda, \theta)$ for the unit increase of $T(\lambda)$.

\begin{tabular}{rr|r|r|r|r|r|r}
\hline \multicolumn{1}{|c|}{$\lambda(\mu)$} & 0.40 & 0.55 & 0.70 & 0.80 & 1.05 & 1.50 \\
\hline $1^{\circ}$ & 4.6 & 10.0 & 16.0 & 24.0 & 35.0 & 42.0 \\
$2^{\circ}$ & 0.9 & 1.9 & 4.8 & 7.0 & 11.5 & 17.6 \\
$3^{\circ}$ & 0.3 & 1.2 & 2.4 & 3.4 & 6.4 & 8.4 \\
\hline
\end{tabular}




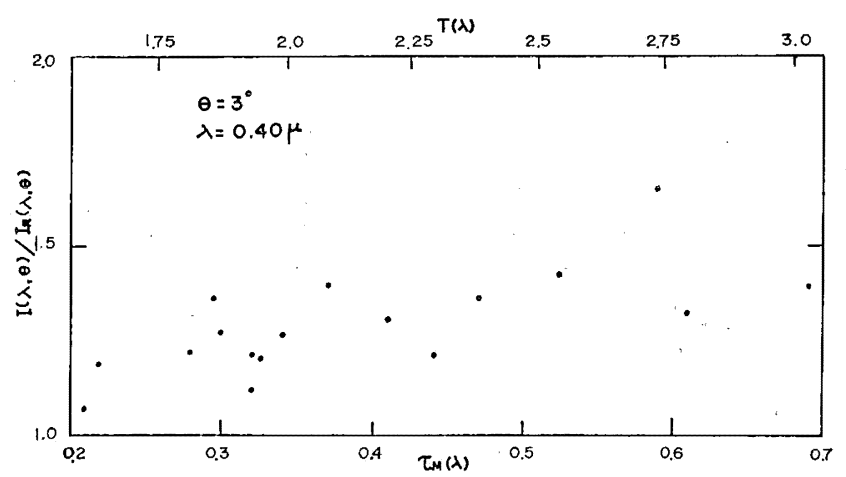

a

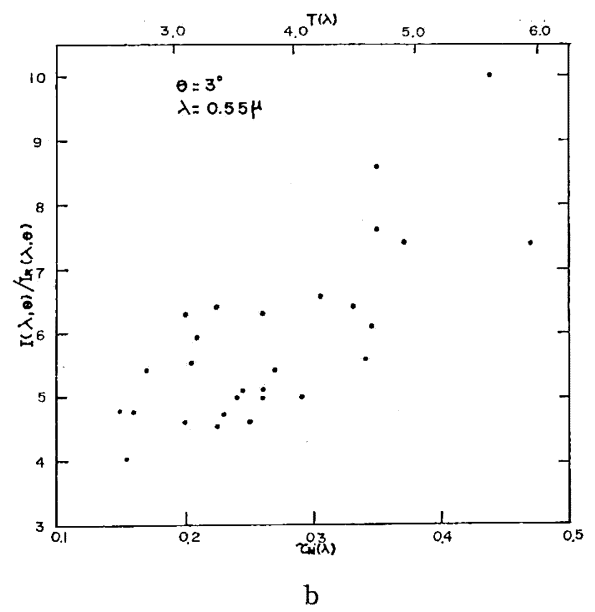

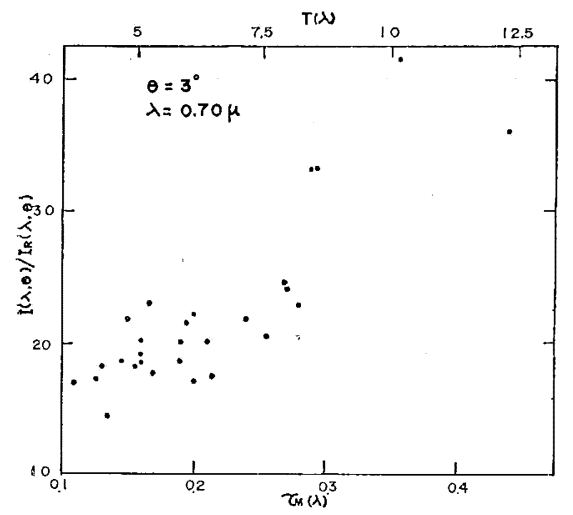

c

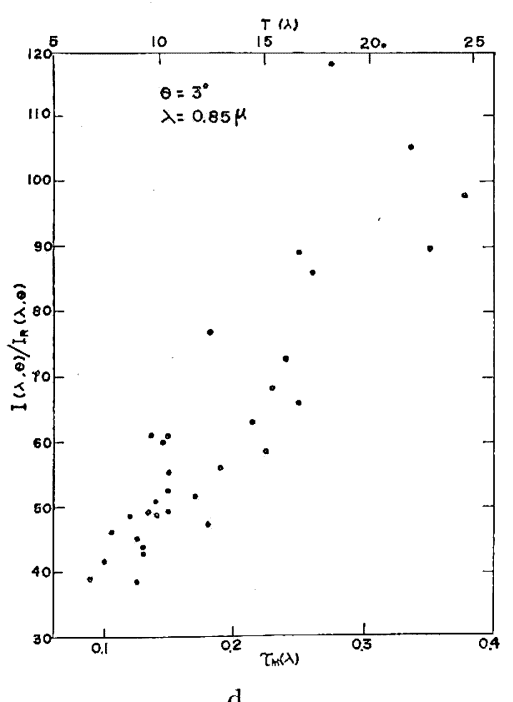



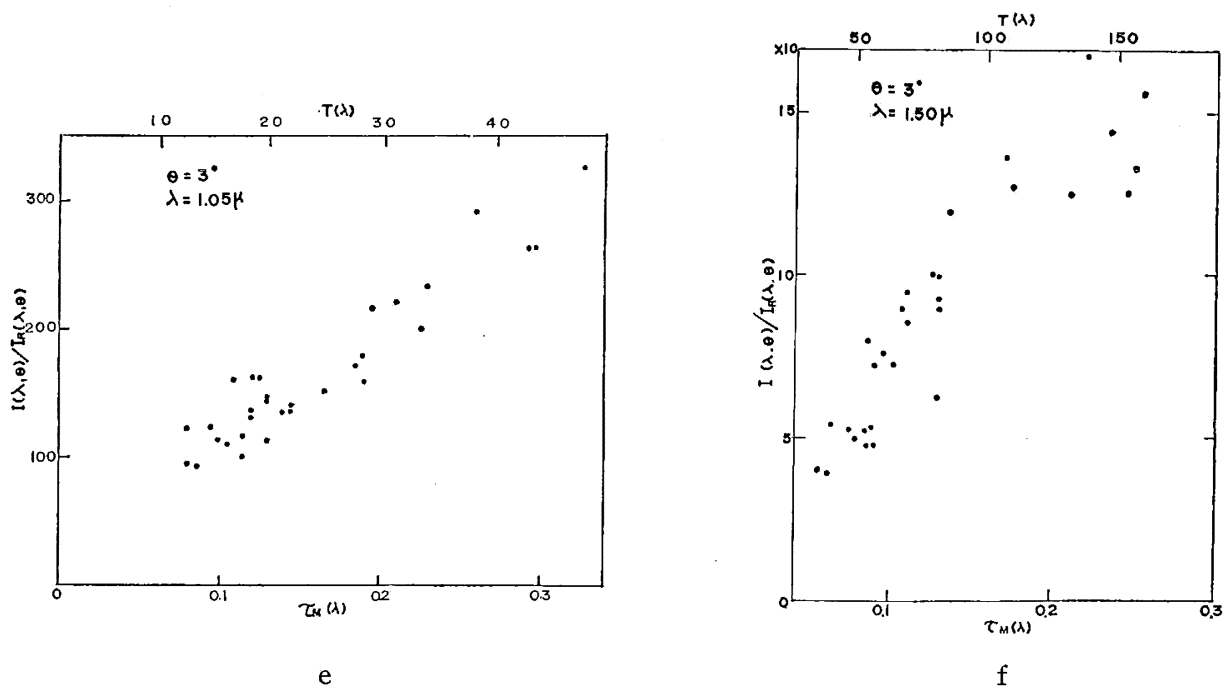

Fig. $46 \mathrm{a}$ to $\mathrm{f}$. Same as Fig. $44 \mathrm{a}$ to $\mathrm{f}$ but for $\theta=3^{\circ}$.

wide range in the figure, we can see the tendency of $\mathrm{R}(\lambda, \theta)$ to increase with increasing $\tau_{M}(\lambda)$ or $T(\lambda)$. The mean increment of $R(\lambda, \theta)$ for that of $T(\lambda)$ are shown in Table 3 .

Although it is somewhat difficult to classify the spectral distributions of aureole intensities into some definite types, those corresponding to the three types of $\tau_{M}(\lambda)$ are characterized as follows;

The spectral distribution of aureole intensity corresponding to Type I is characterized by an abrupt increase of the intensity with increasing wavelength in the short region for $\theta=1^{\circ}$, a slight increase with increasing wavelength in the short and the intermediate regions for $\theta>10^{\circ}$.

The spectral distribution of aureole intensity corresponding to Type II is characterized by a gradual increase of intensity with increasing wavelength in the short and the intermediate regions for $\theta=1^{\circ}$, a small variation in the IR region for $\theta=1^{\circ}$ and a slight decrease with increasing wavelength in the IR region for $\theta>10^{\circ}$.

The spectral distribution of aureole intensity corresponding to Type III is characterized by a steady increase of intensity with increasing wavelength in the short and the intermediate regions and a small increase of the intensity in the IR region for $\theta=1^{\circ}$ and by an increase of intensity with increasing wavelength and a slight decrease with increasing wavelength for $\theta>10^{\circ}$.

The spectral distribution shown in Fig. 20 corresponds to the case where the optical thickness is abnormally large and the slope of the distribution curve is rather steep (see the curve of Nov. 27, 1967 in Fig. 9). In this case, it should be considered that the multiple scattering in the short and the intermediate regions is effective in reducing the intensities in these regions. 
Grey absorption of radiation is considered to be another cause of the decrease of aureole intensity in the short and the intermediate regions, but it is difficult to detect this effect individually in measurements. It is a problem to be studied in future.

\subsection{Angular distributions of aureole intensities}

Many authors investigate the relation between angular distribution of scattered radiation by aerosol particles and aerosol size distribution, because the angular distribution represents the mean phase function of a volume containing particles with various sizes. VOLZ and BULLRICH published a lot of results of measurements and in recent years there are number of measurements of the angular distribution of scattered radiation with a polar nephelometer (PRITCHARD and ELLIOTT, 1960; HOLLAND and DRAPER, 1967). On the other hand, theoretical investgations are developed by DEIRMENDJIAN (1956, 1964) who calculated the phase functions assuming many kinds of size distribution of aerosol particles. BULLRICH and de BARY $(1963,1964)$ also investigated the effects of particles of the larger sizes on scattered radiation.

The angular distributions measured at Mainz by VOLZ and BULLRICH (1961) are shown in Figs. 47 to 49 . The characteristic behavior in their results is that the angular distributions in the near infrared region in the three figures are quite different from each other in their slopes. The slope of angular distribution of $\lambda 0.95 \mu$ in Fig. 47 is nearly the same as that in the visible region, but the slope for $\lambda 0.95 \mu$ in Fig. 49 is the same as that of $\lambda 1.76 \mu$. The slope for $\lambda 0.95 \mu$ in Fig. 48 lies between the curves of $\lambda 0.671 \mu$ and $\lambda 1.76 \mu$. VOLZ and BULLRICH suggest that the number of particles in the larger size region should be larger than that for the power law size distribution for the explanation of the above features of angular distributions. In addition to this, they

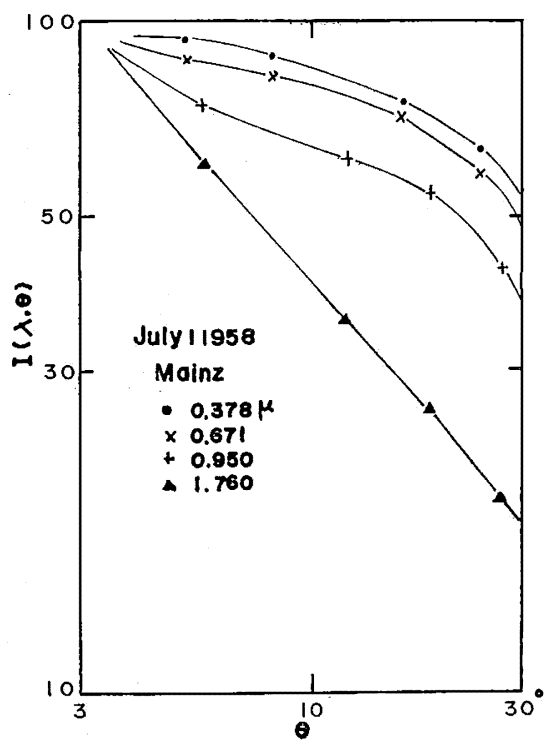

Fig. 47. Angular distribution of sky radiation for the infrared scattering Case I measured by Volz and Bullrich.

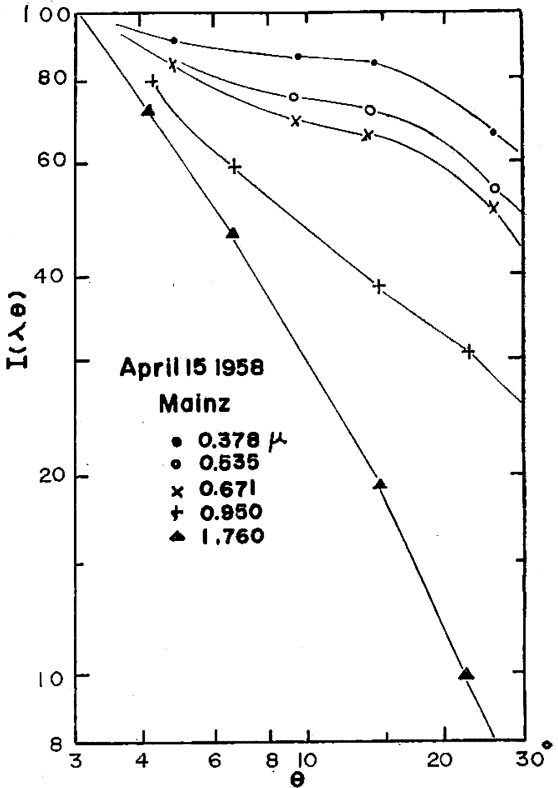

Fig. 48. Same as Fig. 47 but for the infrared scattering Case II. 


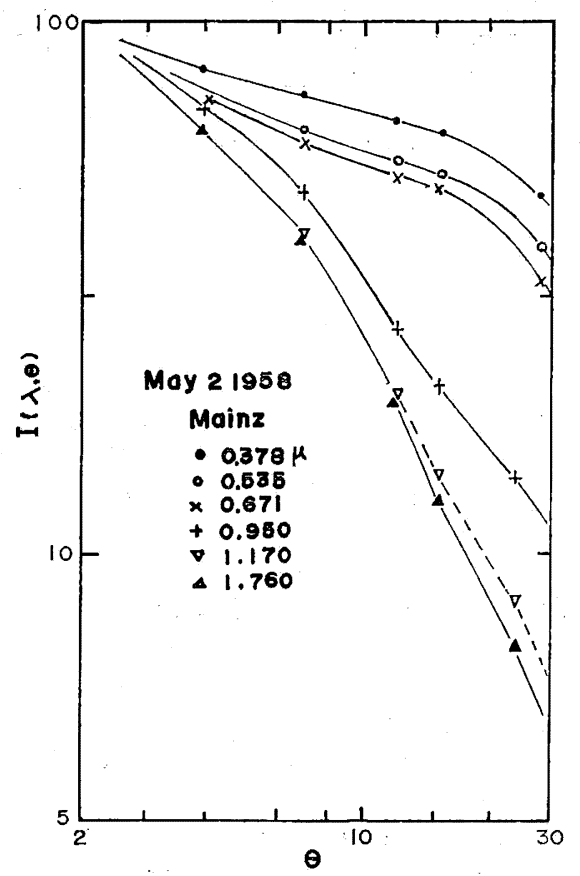

Fig. 49. Same as Fig. 47 for the infrared scattering Case III

suggest that the variation of the chemical and optical properties of particles with the size must be considered for the explanation. In this case we should take into account the variation of refractive index with wavelength. This is also a problem yet to be sloved.

In the angular distributions obtained by the author, the distributions in the IR region do not differ so widely from those in the short and the intermediate regions as the case of VOLZ and BULLRICH. The slopes of angular distributions gradually increase with increasing wavelength and they are generally larger than those of VOLZ and BULLRICH. Comparing the results obtained by the author with each other, one can see that the slopes of augular distributions for Type I are the largest and those for Type II are the smallest. The distributions for Type III vary widely in the slopes.

In order to investigate the empirical relation between the angular distribution of aureole intensity and the size distribution of particles, two indices are used; one of them is defined by $F=\tau_{M}(0.4 \mu) / \tau_{M}(0.8 \mu)-\tau_{M}(0.8 \mu) / \tau_{M}(1.6 \mu) . \quad F=0$ means a linear distribution of $\tau_{M}(\lambda)$ in log-log scale, in the case of $F>0$ the distribution of $\tau_{M}(\lambda)$ is steeper in the shorter wavelength region than in the longer wavelength region and in the case of $F<0$ the distribution is steeper in the longer than in the shorter wavelength region. Another index denotes the behavior of angular distributions of aureole intensities and defined by $A_{D}=I_{r}(1.5 \mu, \theta) / I_{r}(0.4 \mu, \theta)$, where $I_{r}(\lambda, \theta)$ is the aureole intensity at $\theta$ relative to that at $\theta=1^{\circ}$. The index $A_{D}$ denotes a measure of the difference of slopes of angular distributions with wavelength and when all curves of angular distrbutions have nearly the same slopes $A_{D}$ approaches to 1 , and when the slopes widely vary with wavelength $A_{D}$ becomes smaller. The relations between $A_{D}$ and $F$ are shown in Figs. 50 and 51. 


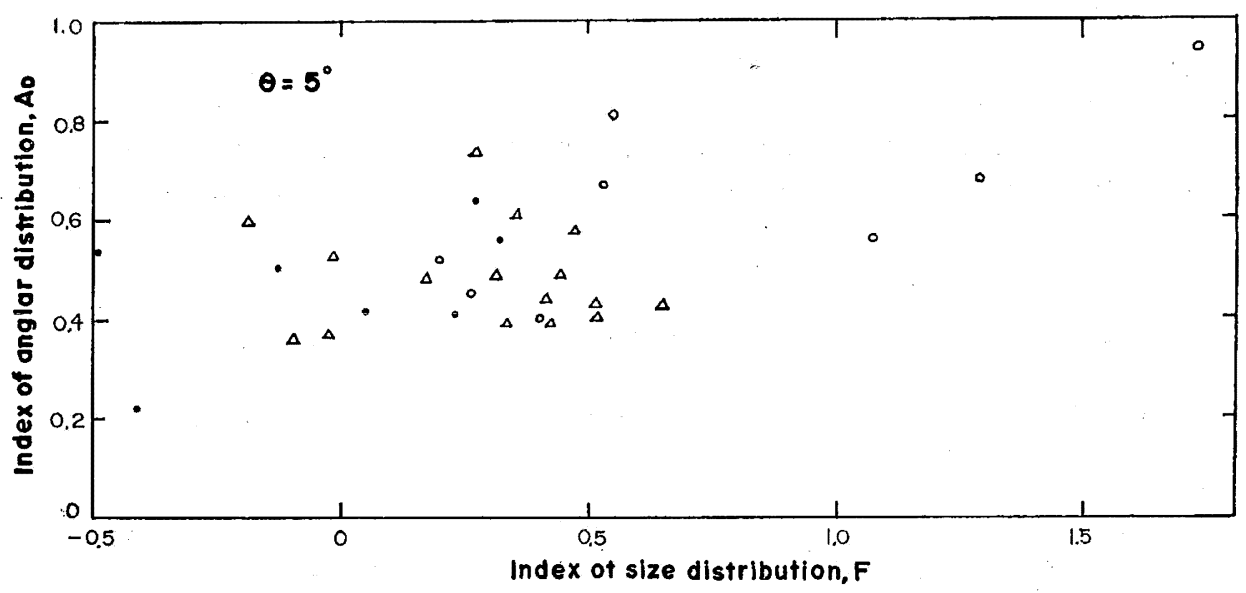

Fig. 50. Relation between the angular distribution of aureole intensity and the size distribution of aerosol particles. $A_{D}$ is the ratio $I_{r}\left(1.5 \mu, 5^{\circ}\right) / I_{r}\left(0.4 \mu, 5^{\circ}\right)$ and $F$ is defined as $F=\tau_{M}(0.4 \mu) / \tau_{M}(0.8 \mu)$ $-\tau_{M}(0.8 \mu) / \tau_{M}(1.6 \mu)$.

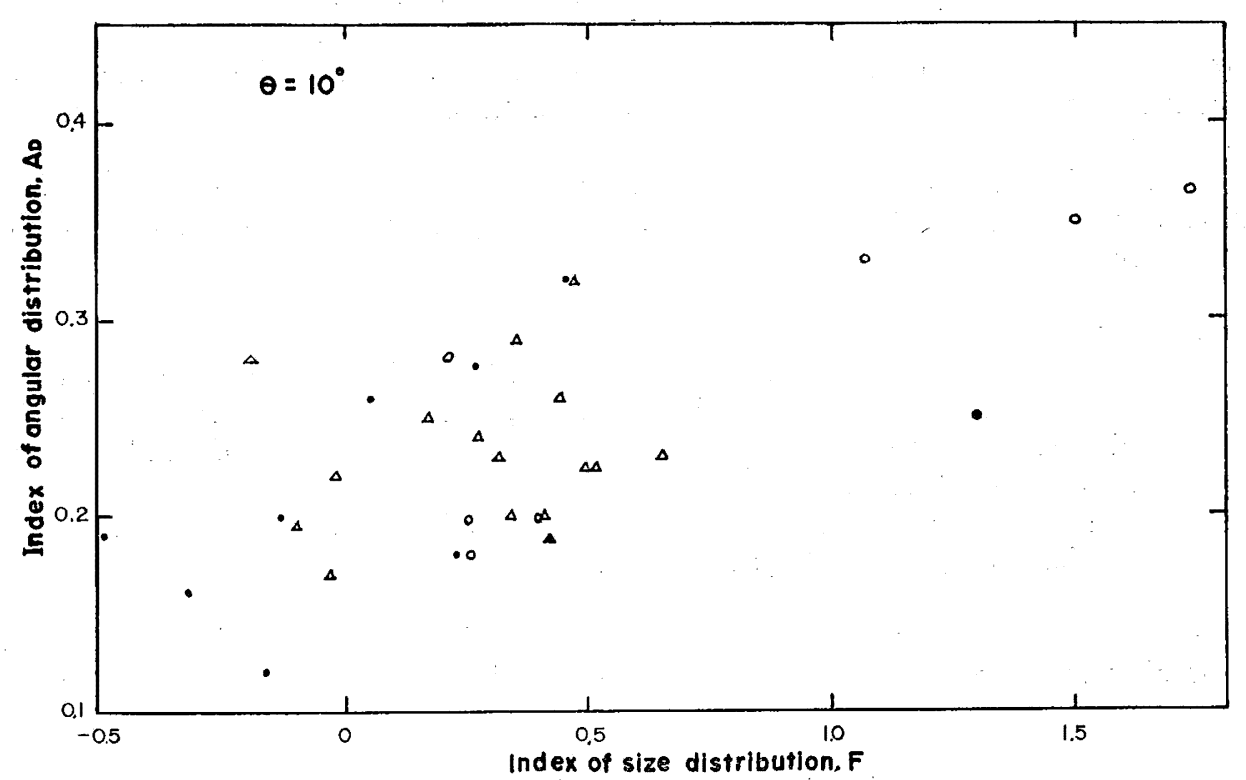

Fig. 51. Same as Fig. 50 but for $\theta=10^{\circ}$.

In these figures, the values of $F$ for Type I lie in the negative or small positive region (indicated by dots in the figures) and $A_{D}$ corresponding to them are relatively small. The values of $F$ for Type II lie in the small positive region (indicated by triangles. in the figures) and the values of $A_{D}$ corresponding to them are slightly larger than the former. The values of $F$ for Type III lie in the positive region (indicated by open dots in the figures) and the values of $A_{D}$ corresponding to them are 
relatively large.

It is difficult to determine the size distribution of aerosol particles from the only behavior of the angular distribution of aureole intensity. However, the empirical relation between $A_{D}$ and $F$ in Figs. 50 and 51 is considered to reflect the effect of size distribution of aerosol particles on $\tau_{M}(\lambda)$ and angular distribution of aureole intensity.

\section{Summary}

The results discussed in the previous chapters are summarized as follows:

(1) An instrument for spectral measurements of the absolute values of direct solar and sky radiations has been designed.

(2) The spectral factors of the instrument which correspond to the spectral energies of solar radiation outside the atmosphere were determined from the intensities of the direct solar radiation measured at a time when optical conditions of the atmosphere were stable. Using the spectral factors of the instrument the absolute values of the spectral intensities of solar and sky radiation are obtained.

(3) The spectral optical thickness of aerosol particles $\tau_{M}(\lambda)$ shows the diurnal variation (Figs. 3 to 7 ) and is generally large around noon.

(4) The spectral distributions of $\tau_{M}(\lambda)$ (Figs. 8 to 16 and Figs. 38 and 39) are classified into the three types as discussed in Sec. 4.1.3.

(5) The size distributions of aerosol particles inferred by comparing these spectral distributions of $\tau_{M}(\lambda)$ with the theoretical investigations by DEIRMENDJIAN and FoITZIK are

Type I a power law size distribution with a rather steep slope in the range $r<0.1 \mu$, a hollow in the range $0.1<r<0.5 \mu$ and a hump in the range $0.5<r<1.0 \mu$,

Type II a combination of four Gaussian groups 1, 2, 3 and 4 in which the number of particles for 1, 2 and 4 are the same as those in Fig. 41 and that for 3 is smaller than that in the figure,

Type III a quasi power law size distribution with a slight increase of the number of particles larger than $1.0 \mu$ in radius.

(6) The aureole intensity increases with increasing wavelength in the region of angular distance $\theta<5^{\circ}$ and increases or decreases with wavelength in the region $\theta>$ $10^{\circ}$.

(7) The aureole intensity increases with increasing optical thickness $\tau_{M}(\lambda)$ or turbidity factor $T(\lambda)$ and the increment with $T(\lambda)$ increases with increasing wavelength (Figs. 44 to 46 ).

(8) The slopes of angular distributions of aureole intensities generally increase with increasing wavelength. The variation of the slope with wavelength is largest for Type I and smallest for Type III.

Acknowledgement-The author is grateful to Prof. G. YAMAMoTo of Tohoku University 
for his helpful suggestions on the problems, especially concerning the measurements in the infrared region. Thanks are due to Dr. SEKIHARA of the Meteorological Research Institute for his support to this work. He is thankful to Dr. M. KANO of the Meteorological Research Institute for his kind suggestions and critical reading of the manuscript. Mr. M. SUZUKI and Mr. Y. OGAWA kindly assisted him in the measurements and arrangement of data. And finally, he wishes to thank Miss H. UCHIDA for her assistance in the arrangement of data and preparation of illustrations.

\section{References}

AldRICH, L.B. and W.H. Hoover, 1954 : Annals Astrophys. Observ. VII, Washington, (U.S. Govt. Printing Office).

Anthony, R., 1953: Observations of non-Rayleigh scattering in the spectrum of the day sky in the region 0.56 to 2.2 microns. J. Met., 10, 60-63.

BULlRICH, K., 1960: Streulichtmessungen in Dunst und Nebel. Met. Runds., 13, 21-29.

de BARY, E. and K. BULlRICH, 1963: Uber den Anteil der Rayleigh-Streuung und den Einfluss der Aerosol-Grössenverteilung auf Extinktion und spectrale Intensität der Streustrahlung eines Luftvolumens. Arch. Met. Geophys. Bioklima, Ser. B, 12, 254-277.

— - 1964: Die Berechnung der Himmelstrahlung mit Berücksichtiguung der Aerosole und der Mehrfachstreuung. Optik, 21, 467-488.

DeIRMENDJiAn, D., 1959: The role of water particles in the atmospheric transmission of infrared radiation. Quart. J. Roy. Met. Soc., 85, 404-411.

___ 1960: Atmospheric extinction of infrared radiation. Quart. J. Roy. Met. Soc., 86, 371-381. -, 1956: Atmospheric scattering of light and the sun's aureole. Los Angeles, Univ. of Calif.

- 1964 : Scattering and polarization proporties of water clouds and hazes in the visible and infrared. App. Opt., 3, 187-196.

FoITZIK, L., 1965: The spectral extinction of the atmospheric aerosol by Mie particles with different Gaussian distributions. Gerlands Beitr. z. Geoph., 73, 199-206.

Holland, A.C. and J.S. DRAPER, 1967: Analytical and experimental investigation of light scattering from polydispersions of Mie particles. App. Opt., 6, 511-517.

Pritchard, B.S. and W.G. ElliotT, 1960: Two instruments for atmospheric optics measurements. J. Opt. Soc. Amer., 50, 191-202.

Rose, H.E., 1952: Determination of the "Extinction coefficient" - - particle size relationship for spherical particles. J. App. Chem., 2, 80-88.

Volz, F.E. and K. BULlRICH, 1961: Scattering function and polarization of skylight in the ultraviolet to the near infrared region, with haze of scattering type 2. J. Met., 18, 306-318.

\section{太陽直射光および周辺光の分光測定（II）}

一一近赤外域の測定——

村井潔 三

装置の詳細と紫外，可視域に䑙ける測定の結果をP Part I に述べたが，エーロゾルの粒径分布を推定す るためには近赤外域の測定が極めて重要であるので, この領域の測定を容易にするために装置の改良を行 い新しい装置を作製した。また，古い装置に叔ける測定誤差の主な原因と思われる部分の改良もほどこし てある。 
直射光の測定から得られたエーロゾルの光学的厚さの波長分布は 3 つの型に分類される。Foitzik 牧よび Deirmendjian の計算結果と比較して推論された粒径分布は上の 3 つの型に対応して次の様に表わされる。

Type I 粒子半径 $r<1.0 \mu$ の領域では steep な power law 分布を示し, $0.1<r<0.5 \mu$ では分布曲 線は hollow を示し, $0.5<r<1.0 \mu$ では hump を示している。

Type II Foitzik の仮定した 4 つの Gaussian group の組合わせにより表わされるが, $0.5<r<1.0 \mu$ の領域に存在する Gaussian group の粒子数は Foitzik の仮定したものよりす僅かに少い。

Type III かなり steep な power law 分布により表わされ， $r>1.0 \mu$ の領域では分布曲線の傾斜は 僅か減少している。

周辺光の強度は太陽からの角度 $\theta<5^{\circ}$ の領域では波長と共に増加する分布を示し， $\theta>10^{\circ}$ の領域では変 化は非常に少く, あるいわ，僅かに波長と共に減少する傾向を示している。周辺光強度の大気外值に対す る相対值は $\theta=1^{\circ}$ ではほほ $10^{-4}$ の order を示し, $2<\theta<5^{\circ}$ では $10^{-5}$ の order, $\theta>10^{\circ}$ ではほぼ $10^{-6}$ の order である。

周辺光の強度は大気の混濁度の増加と共に増加し, 混濁度の増加に対する周辺光強度の増加の割合は波 長が大さい程大きい。

周辺光強度の波長分布の型は明確な分類は難かしいが，前述の粒径分布の Type I に対応する波長分布 は波長 $\lambda<0.5 \mu$ の領域で急激な增加を示し, Type II に対応する分布は波長と共にゆるやか増加する傾 向を示している。Type III に対応する分布は Type II に比して急激な増加を示す曲線で表わされる。

周辺光強度の角度分布の傾斜は波長と共に増加し, Volz, Bullrich 等の測定よりる傾斜は急である。ま た, Deirmendjian の計算結果と比べると角度分布の傾斜は非常に急である。

分布曲線の傾斜の波長による变化は Type I の粒径分布に対応する場合に最も大きく, Type III の場合 に最す小さい。 